NBER WORKING PAPER SERIES

\title{
A THEORY OF HOUSING COLLATERAL, CONSUMPTION INSURANCE AND RISK PREMIA
}

\author{
Hanno Lustig \\ Stijn Van Nieuwerburgh \\ Working Paper 10955 \\ http://www.nber.org/papers/w10955 \\ NATIONAL BUREAU OF ECONOMIC RESEARCH \\ 1050 Massachusetts Avenue \\ Cambridge, MA 02138 \\ December 2004
}

The authors thank Thomas Sargent, Dave Backus, Andrew Abel, Fernando Alvarez, Timothey Cogley, Harold Cole, Steven Grenadier, Robert Hall, Lars Peter Hansen, Urban Jermann, Narayana Kocherlakota, Dirk Krueger, Martin Lettau, Sydney Ludvigson, Sergei Morozov, Lee Ohanian, Monika Piazzesi, Martin Schneider, Kenneth Singleton, Laura Veldkamp, Pierre-Olivier Weill and Amir Yaron. We also benefited from comments from seminar participants at Duke University, Stanford GSB, University of Iowa, Universite de Montreal, New York University Stern, University of Wisconsin, University of California at San Diego, London Business School, London School of Economics, University College London, University of North Carolina, Federal Reserve Bank of Richmond, Yale University, University of Minnesota, University of Maryland, Federal Reserve Bank of New York, Boston University, University of Pennsylvania Wharton, University of Pittsburgh, Carnegie Mellon University GSIA, Northwestern University Kellogg, University of Texas at Austin, Federal Reserve Board of Governors, University of Gent, UCLA, University of Chicago, Stanford University, the Society for Economic Dynamics Meeting in New York, and the North American Meeting of the Econometric Society in Los Angeles. For computing support we thank NYU Stern, especially Norman White. Stijn Van Nieuwerburgh acknowledges financial support from the Stanford Institute for Economic Policy research and the Flanders Fund for Scientific Research. This project was started while Lustig was at the University of Chicago. The views expressed herein are those of the author(s) and do not necessarily reflect the views of the National Bureau of Economic Research.

(C) 2004 by Hanno Lustig and Stijn Van Nieuwerburgh. All rights reserved. Short sections of text, not to exceed two paragraphs, may be quoted without explicit permission provided that full credit, including () notice, is given to the source. 
A Theory of Housing Collateral, Consumption Insurance and Risk Premia Hanno Lustig and Stijn Van Nieuwerburgh

NBER Working Paper No. 10955

December 2004, Revised February 2006

JEL No. G0

\begin{abstract}
$\underline{\text { ABSTRACT }}$
In a model with housing collateral, a decrease in house prices reduces the collateral value of housing, increases household exposure to idiosyncratic risk, and increases the conditional market price of risk. This collateral mechanism can quantitatively replicate the conditional and the cross-sectional variation in risk premia on stocks for reasonable parameter values. The increase of the conditional equity premium and Sharpe ratio when collateral is scarce in the model matches the increase observed in US data. The model also generates a return spread of value firms over growth firms of the magnitude observed in the data, because the term structure of consumption strip risk premia is downward sloping.

Hanno Lustig

Department of Economics

UCLA

Box 951477

Los Angeles, CA 90095-1477

and NBER

hlustig@econ.ucla.edu

Stijn Van Nieuwerburgh

NYU Stern School of Business

$44 \mathrm{~W}$ Fourth Street

New York, NY 10012

svnieuwe@stern.nyu.edu
\end{abstract}




\section{Introduction}

The canonical consumption-based asset pricing model of Breeden (1979) and Lucas (1978) implies small and roughly constant equity risk premia over time and little or no risk premium variation in the cross-section. Yet, recent research in empirical asset pricing has documented striking differences in risk premia between equity and bonds, between equity at different points in time, and between portfolios formed by sorting equities on their book-to-market ratio. Time-variation in risk premia, documented, among others, by Ferson and Harvey (1991) and Whitelaw (1997)), implies that returns are predictable (Cochrane (2001)). Many papers have documented predictability, especially at longer holding periods. ${ }^{1}$ The predictability comes mostly from changes in risk premia, rather than changes in expected dividend growth (Campbell and Shiller (1988)). Recently, Jagannathan, McGrattan and Scherbina (2000) and Fama and French (2002) have argued that there has been a long-run decline in US risk premia. Risk premia also vary substantially across securities. According to Fama and French (1992), value stocks earn returns that are on average six percent higher than growth stocks; this premium is of the same size as the equity risk premium itself.

The two most common approaches to tackling the shortcomings of the Lucas-Breeden model are changing the preferences ${ }^{2}$, or changing the dynamics of the aggregate consumption process. ${ }^{3}$ The most successful model in the first class is arguably the habit formation model. However, it is hard to find direct empirical evidence for this specification of preferences and habit-style preferences have unappealing public policy implications (Ljungqvist and Uhlig (2000)). As for the second approach, it is hard to distinguish between i.i.d. consumption growth and a specification that includes a small, predictable component based on the avail-

\footnotetext{
${ }^{1}$ Fama and French (1988), Campbell and Shiller (1988), Cochrane (1991), Goetzman and Jorion (1993), Hodrick (1992), and Lettau and Van Nieuwerburgh (2005) find that the dividend-price ratio has predictive power. Other variables have also been found to be powerful predictors of long horizon returns (e.g. Lamont (1998), Lettau and Ludvigson (2001), Menzly, Santos and Veronesi (2004), and Lustig and Van Nieuwerburgh (2005a).

${ }^{2}$ Habit style preferences are most commonly used, see Abel (1990), Constantinides (1990), Ferson and Constantinides (1991), Abel (1999), Campbell and Cochrane (1999), and Menzly et al. (2004) for early contributions. Another approach is to model non-separable preferences over a second good, such as housing (Flavin (2001) and Piazzesi, Schneider and Tuzel (2004)) or durables (Dunn and Singleton (1986), Eichenbaum and Hansen (1990), and Yogo (2005))

${ }^{3}$ Bansal and Yaron (2004) introduce a small but very persistent component in aggregate consumption and dividend growth. Bekaert, Engstrom and Grenadier (2004) combine this specification with habit style preferences.
} 
able data. Furthermore, these models can only address the long-run decline in the US equity premium through a radical change in the time series process for aggregate consumption growth, which again is hard to detect in the data. ${ }^{4}$

Instead of staying within the representative agent framework, we introduce heterogeneity among agents. Our focus is on the impact of time variation in risk sharing on asset prices. In the model, households differ only by their income histories. They share income risk by trading contingent claims, but they cannot borrow more than the value of their house. When housing collateral is scarce, collateral constraints constrain risk sharing more, and, as a result, risk premia are higher. Thus, risk premia vary over time and with the housing collateral ratio. This modest friction is a realistic one for an advanced economy like the US. ${ }^{5}$

The main contribution of this paper is to demonstrate that the endogenous time variation in the amount of housing collateral can quantitatively account for three of the differences in expected returns: between equity and the risk-free asset, between equity at different points in time, and between value and growth portfolios. In addition, our model replicates the long-run decline in the equity premium and in the volatility of the risk-free rate in the US during the second half of the 20th century. This paper fits in a broader research agenda that includes Lustig and Van Nieuwerburgh (2005a) and Lustig and Van Nieuwerburgh (2005b). The second paper explains why regional consumption growth in the US is more cross-correlated when the housing collateral supply increases. This finding offers direct support for the collateral mechanism. In the first paper, we test our model's Euler equation on the cross-section of US stock returns. To do so, we take the returns from the data and we approximate the wealth distribution, an unobservable, as a function of the collateral ratio and consumption shocks. Our results provide qualitative support for the mechanism. In the current paper, we generate the returns and the wealth distribution dynamics inside

\footnotetext{
${ }^{4}$ Lettau, Ludvigson and Wachter (2005) explore the effect of the apparent decline in aggregate consumption growth volatility.

${ }^{5}$ Our emphasis on housing, rather than financial assets, reflects three features of the US economy: the participation rate in housing markets is very high ( $2 / 3$ of households own their home), the value of the residential real estate makes up over seventy-five percent of total assets for the median household (Survey of Consumer Finances, 2001), and housing is a prime source of collateral (75 percent of household borrowing in the data is collateralized by housing wealth, US Flow of Funds, 2003). To keep the model exposition simple, we abstract from financial assets or other kinds of capital (such as cars) that households may use to collateralize loans. However, in the calibration we explore the effects of using a broader measure of collateral.
} 
the model, and we show the fluctuations in housing collateral can quantitatively explain the variation in expected returns in a DSGE model, a key step in advancing the collateral mechanism as a serious candidate for understanding asset returns.

Outline We start by briefly setting up the model (section 1) and focus on its asset pricing implications. The households trade a complete menu of assets, as in Lucas (1978), but they face endogenous solvency constraints because they can repudiate their debts. When a household chooses to repudiate its debts, it loses all its housing wealth but its labor income is protected from creditors. The household is not excluded from trading. ${ }^{6}$ We carefully calibrate the model in section 2 .

As a first test, we feed the model seven decades worth of US data on aggregate consumption growth and housing collateral ratio dynamics (section 3). We solve for the model-implied equity premium and risk-free rate. After the great depression, the housing collateral ratio decreases substantially which causes a dramatic increase in the equity premium and in the risk-free rate volatility in the model. We document the same pattern in the data. In our model, the subsequent increase in the US housing collateral ratio since the 1950s (the mortgage to income ratio increases from $12 \%$ to $100 \%$ ) produces a decline in the equity premium from $11 \%$ to $3.5 \%$ in 2002, consistent with the findings of Jagannathan et al. (2000). Equity holders in the model earn large unexpected capital gains, especially in the 1990s. This is what Fama and French (2002) find in the data. We also document a strong positive relationship in the data between the housing wealth-to-income ratio and the risk-free rate, the key signature of the collateral mechanism in our model. Finally, we replicate the decline in the volatility of stock and bond returns after the 1940s.

The model has two more distinguishing time-series properties. First, it implies that a lower ratio of housing collateral wealth to total wealth, henceforth the housing collateral ratio, predicts higher future excess returns. The predictability of returns in the model

\footnotetext{
${ }^{6}$ In Kehoe and Levine (1993), Krueger (2000), Kehoe and Perri (2002), and Krueger and Perri (2005), limited commitment is also the source of incomplete risk-sharing. But the outside option upon default is exclusion from all future risk sharing arrangements. Alvarez and Jermann (2000) show how to decentralize these Kehoe and Levine (1993) equilibria with sequential trade. Geanakoplos and Zame (2000) and Kubler and Schmedders (2003) consider a different environment in which individual assets collateralize individual promises in a standard incomplete markets economy. We model the outside option as bankruptcy with loss of all collateral assets; all promises are backed by all collateral assets.
} 
quantitatively matches the evidence in US stock returns documented in Lustig and Van Nieuwerburgh (2005a). Second, the Sharpe ratio in the model is highly volatile, an important feature of US data not accounted for by most equilibrium models. It also moves inversely with the housing collateral ratio in US data. Figure 1 shows that the model's expected excess return on equity (panel 1), its conditional volatility (panel 2), and the conditional Sharpe ratio (panel 3) are all decreasing functions of the amount of housing collateral available in the economy (horizontal axis).

[Figure 1 about here.]

The model also explains why risk premia vary so much across securities. According to Fama and French (1992), value stocks earn returns that are on average six percent higher than growth stocks. Our model replicates this feature of the data (section 4). Figure 2 shows that return spreads on book-to-market sorted portfolios predicted by the model line up nicely with the same spreads in the data. Our model endogenously generates a positive value premium when value stocks are short-duration assets. The reason lies in the term structure of consumption risk premia it generates. In a recent paper, Lettau and Wachter (2005) point out that, if value stocks are short-duration stocks and growth stocks longduration stocks, a positive value premium requires the term structure of consumption risk premia to be downward sloping. Yet, the habit formation model of Campbell and Cochrane (1999) generates an upward sloping term structure of consumption risk premia: Since a bad consumption shock increases discount rates almost permanently, the price of long-maturity consumption claims would fall by more. In other words, growth stocks would earn a larger risk premium. In contrast, a bad consumption shock in our model increases discount rates temporarily. It does not affect the collateral ratio, which governs discount rates in the long run. As a result, the price of consumption strips of longer maturity is insulated from bad consumption shocks today. This generates lower expected returns on growth stocks than value stocks.

[Figure 2 about here.]

Finally, section 5 explains in detail the equilibrium dynamics of the two driving forces: 
the wealth distribution and the collateral ratio. It shows how these interact to deliver high equity premia, volatile equity premia, and high Sharpe ratios when collateral is scarce.

The appendix provides proofs of the propositions, it details an additional procedure to calibrate the average housing collateral ratio, it describes the computational algorithm, and it discusses the model's implications for unconditional asset pricing moments.

\section{Model}

Since the focus of our paper is on the quantitative asset pricing predictions, we keep the discussion of the model brief.

\subsection{Environment}

Uncertainty The economy is populated by a continuum of infinitely lived households. The structure of uncertainty is twofold: $s=(y, z)$ is an event that consists of a household-specific component $y \in Y$ and an aggregate component $z \in Z$. These events take on values on a discrete grid $S=Y \times Z$. We use $s^{t}=\left(y^{t}, z^{t}\right)$ to denote the history of events. $S^{t}$ denotes the set of possible histories up until time $t$. $s$ follows a Markov process with transition probabilities $\pi$ that obey:

$$
\pi\left(z^{\prime} \mid z\right)=\sum_{y^{\prime} \in Y} \pi\left(y^{\prime}, z^{\prime} \mid y, z\right) \forall z \in Z, y \in Y
$$

Because of the law of large numbers, $\pi_{z}(y)$ denotes both the fraction of households drawing $y$ when the aggregate event is $z$ and the probability that a given household is in state $y$ when the aggregate state is $z .^{7}$

Preferences We use $\{x\}$ to denote an infinite stream $\left\{x_{t}\left(s^{t}\right)\right\}_{t=0}^{\infty}$. There are two types of commodities in this economy: a consumption good $c$ and housing services $h$. These commodities cannot be stored. The households rank consumption streams according to the

\footnotetext{
${ }^{7}$ The usual caveat applies when applying the law or large numbers. We implicitly assume the technical conditions outlined by Uhlig (1996) are satisfied.
} 
criterion:

$$
U(\{c\},\{h\})=\sum_{s^{t} \mid s_{0}} \sum_{t=0}^{\infty} \delta^{t} \pi\left(s^{t} \mid s_{0}\right) u\left(c_{t}\left(s^{t}\right), h_{t}\left(s^{t}\right)\right),
$$

where $\delta$ is the time discount factor. The households have power utility over a CES-composite consumption good:

$$
u\left(c_{t}, h_{t}\right)=\frac{\left[c_{t}^{\frac{\varepsilon-1}{\varepsilon}}+\psi h_{t}^{\frac{\varepsilon-1}{\varepsilon}}\right]^{\frac{(1-\gamma) \varepsilon}{\varepsilon-1}}}{1-\gamma} .
$$

The parameter $\psi>0$ converts the housing stock into a service flow, $\gamma$ captures the degree of relative risk aversion, and $\varepsilon$ is the intratemporal elasticity of substitution between nondurable consumption and housing services. ${ }^{8}$

Endowments The aggregate endowment of the non-durable consumption good is denoted $\left\{c^{a}\right\}$. The growth rate of the aggregate endowment depends only on the current aggregate state: $c_{t+1}^{a}\left(z^{t+1}\right)=\lambda\left(z_{t+1}\right) c_{t}^{a}\left(z^{t}\right)$. Each household is endowed with a labor income stream $\{\eta\}$. The labor income share $\hat{\eta}\left(y_{t}, z_{t}\right)=\eta\left(y_{t}, z^{t}\right) / c^{a}\left(z^{t}\right)$, only depends on the current state of nature. Since the aggregate endowment is the sum of the individual endowments,

$$
\sum_{y^{\prime} \in Y} \pi_{z}\left(y^{\prime}\right) \hat{\eta}_{t}\left(y^{\prime}, z\right)=1, \forall z, t \geq 0
$$

The aggregate endowment of housing services is denoted $\left\{h^{a}\right\}$ and $\rho\left(z^{t}\right)$ denotes the relative price of a unit of housing services. The calibration specifies a process for the ratio of non-housing expenditures and housing services expenditures $\{r\}, r\left(z^{t}\right)=\frac{c^{a}\left(z^{t}\right)}{\rho\left(z^{t}\right) h^{a}\left(z^{t}\right)}$, rather than for $\left\{h^{a}\right\}$ directly.

Trading Each household is assigned a label $\left(\ell, s_{0}\right)$, where $\ell$ denotes the time-zero collateral wealth of this household. The cross-sectional distribution of initial non-labor wealth and income states $\left(\ell, s_{0}\right)$ is denoted $\mathcal{L}_{0} \cdot{ }^{9}$ We let $\left\{c\left(\ell, s_{0}\right)\right\}$ denote the stream of consumption and we let $\left\{h\left(\ell, s_{0}\right)\right\}$ denote the stream of housing services of a household of type $\left(\ell, s_{0}\right)$. The

\footnotetext{
${ }^{8}$ The preferences belong to the class of homothetic power utility functions of Eichenbaum and Hansen (1990). Special cases are separability $\left(\varepsilon=\gamma^{-1}\right)$ and Cobb-Douglas preferences $(\varepsilon=1)$.

${ }^{9} \mathrm{So}, \ell$ denotes the value of the initial claim to housing wealth as well as any financial wealth that is in zero net aggregate supply. In the model there is no financial wealth in positive net supply, but in the calibration we consider augmenting the collateral stock to include realistic values of other financial wealth.
} 
financial markets are complete: households trade a complete set of contingent claims $a$ in forward markets, where $a_{t}\left(\ell, s^{t}, s^{\prime}\right)$ is a promise made by agent $\left(\ell, s_{0}\right)$ to deliver one of unit the consumption good if event $s^{\prime}$ is realized in the next period. These claims are in zero net supply, and trade at prices $q_{t}\left(s^{t}, s^{\prime}\right) .{ }^{10}$ All prices are quoted in units of the non-durable consumption good. There are frictionless rental markets and markets for home ownership; ownership and housing consumption are separated. The rental price is $\rho_{t}\left(z^{t}\right) ; p_{t}^{h}\left(z^{t}\right)$ denotes the (asset) price of the housing stock. Because of the law of large numbers, these prices only depend on aggregate histories.

At the start of each period, the household purchases non-housing consumption in the spot market $c_{t}\left(\ell, s^{t}\right)$, housing services in the rental market $h_{t}^{r}\left(\ell, s^{t}\right)$, contingent claims in the financial market and ownership shares in the housing stock $h_{t+1}^{o}\left(\ell, s^{t}\right)$ subject to a wealth constraint:

$$
c_{t}\left(\ell, s^{t}\right)+\rho_{t}\left(z^{t}\right) h_{t}^{r}\left(\ell, s^{t}\right)+\sum_{s^{\prime}} q_{t}\left(s^{t}, s^{\prime}\right) a_{t}\left(\ell, s^{t}, s^{\prime}\right)+p_{t}^{h}\left(z^{t}\right) h_{t+1}^{o}\left(\ell, s^{t}\right) \leq W_{t}\left(\ell, s^{t}\right) .
$$

Next period wealth is labor income, plus assets, plus the cum-dividend value of owned housing:

$$
W_{t+1}\left(\ell, s^{t}, s^{\prime}\right)=\eta_{t+1}\left(s^{t}, s^{\prime}\right)+a_{t}\left(\ell, s^{t}, s^{\prime}\right)+h_{t+1}^{o}\left(\ell, s^{t}\right)\left[p_{t+1}^{h}\left(z^{t}, z^{\prime}\right)+\rho_{t+1}\left(z^{t}, z^{\prime}\right)\right] .
$$

Collateral Constraints Households can default on their debts. When the household defaults, it keeps its labor income in all future periods. The household is not excluded from trading, even in the same period. However, all collateral wealth is taken away. As a result, the markets impose a solvency constraint that keeps the households from defaulting: all of a household's state-contingent promises must be backed by the cum-dividend value of its housing owned at the end of period $t, h_{t+1}^{o}$. In each node $s^{t}$, households face a separate collateral constraint for each future event $s^{\prime}$ :

$$
-a_{t}\left(\ell, s^{t}, s^{\prime}\right) \leq h_{t+1}^{o}\left(\ell, s^{t}\right)\left[p_{t+1}^{h}\left(z^{t+1}\right)+\rho_{t+1}\left(z^{t+1}\right)\right] \text {, for all } s^{t}, s^{\prime} .
$$

\footnotetext{
${ }^{10}$ This setup is equivalent to having financial intermediaries trade in state contingent claims and provide insurance to the households (Atkeson and Lucas (1993)).
} 
As in Alvarez and Jermann (2000), these constraints are not too tight: they allow for the maximal degree of risk sharing, given that agents cannot be excluded from trading, while preventing default.

\subsection{Equilibrium Asset Prices}

Competitive Equilibrium. Given a distribution over initial non-labor wealth and initial states $\mathcal{L}_{0}$, a competitive equilibrium is a feasible allocation $\left\{c\left(\ell, s^{t}\right), h^{r}\left(\ell, s^{t}\right), a\left(\ell, s^{t}\right), h^{o}\left(\ell, s^{t}\right)\right\}$ and prices $\left\{q, p^{h}, \rho\right\}$ such that (i) for given prices and initial wealth, the allocation solves each household's maximization problem (1) s.t. (2), (3) and (4), and (ii) the markets for the consumption good, the housing services, the contingent claims and housing ownership shares clear.

As in other endogenously incomplete markets models, assets are priced by the unconstrained agents at every date and state (Alvarez and Jermann (2000)). These unconstrained households have the highest intertemporal marginal rate of substitution (IMRS), equal to the stochastic discount factor (SDF) $m$ :

$$
m_{t+1}=\max _{i \in[0,1]}\left\{\delta \frac{u_{c}\left(c_{t+1}^{i}, h_{t+1}^{i}\right)}{u_{c}\left(c_{t}^{i}, h_{t}^{i}\right)}\right\}=\max _{i \in[0,1]}\left\{\delta\left(\frac{c_{t+1}^{i}}{c_{t}^{i}}\right)^{-\gamma}\left(\frac{1+r_{t+1}^{-1}}{1+r_{t}^{-1}}\right)^{\frac{1-\varepsilon \gamma}{\varepsilon-1}}\right\} .
$$

The second equality follows from the form of the utility function, the definition of the expenditure ratio $r=\frac{c^{a}}{\rho h^{a}}$, and market clearing in the housing market. ${ }^{11}$ No arbitrage implies that the return on any security $j, R_{t+1}^{j}$, satisfies the standard Euler equation $E_{t}\left[m_{t+1} R_{t+1}^{j}\right]=1$.

\section{Calibration}

There are two driving forces in the model: the income process and the non-housing expenditure ratio.

\footnotetext{
${ }^{11}$ The equilibrium rental price is $\rho_{t}=u_{h}\left(c_{t}^{i}, h_{t}^{i}\right) / u_{c}\left(c_{t}^{i}, h_{t}^{i}\right)=\psi\left(h_{t}^{i} / c_{t}^{i}\right)^{-\frac{1}{\varepsilon}}, \forall i$. Since there is one economywide rental market, the rental price only depends on aggregate quantities: $\rho_{t}\left(z^{t}\right)=\psi\left(h_{t}^{a}\left(z^{t}\right) / c_{t}^{a}\left(z^{t}\right)\right)^{-\frac{1}{\varepsilon}}$. Consequently, all households equate their non-housing to housing consumption ratios $r\left(z^{t}\right)$.
} 
Income Process The first driving force in the model is the Markov process for the nondurable endowment process. It has an aggregate and an idiosyncratic component. The aggregate endowment growth process is taken from Mehra and Prescott (1985) and replicates the moments of aggregate consumption growth in the 1871-1979 data. Aggregate endowment growth, $\lambda$, follows an autoregressive process:

$$
\lambda_{t}\left(z_{t}\right)=\rho_{\lambda} \lambda_{t-1}\left(z_{t-1}\right)+\varepsilon_{t}
$$

with $\rho_{\lambda}=-.14, E(\lambda)=.0183$ and $\sigma(\lambda)=.0357$. We discretize the $\operatorname{AR}(1)$ process with two aggregate growth states $z=(e x, r e)=[1.04, .96]$ (for expansion and recession) and an aggregate state transition matrix $[.83, .17 ; .69, .31]$. The implied ratio of the probability of a high aggregate endowment growth state to the probability of a low aggregate endowment growth state is 2.65. The unconditional probability of a low endowment growth state is $27.4 \%$. This matches the observed frequency of recessions.

The idiosyncratic labor income volatility in the US increases in recessions (Storesletten, Telmer and Yaron (2004)). Our calibrated labor income process shares this feature. Following Alvarez and Jermann (2001), log labor income shares follow an AR(1) process with autocorrelation of .92, and a conditional variance of .181 in low and .0467 in high aggregate endowment growth states. Discretization into a four-state Markov chain results in individual income states $\left(\eta^{1}(h i, e x), \eta^{1}(l o, e x)\right)=[.6578, .3422]$ in the high and $\left(\eta^{1}(h i, r e), \eta^{1}(l o, r e)\right)=[.7952, .2048]$ in the low aggregate endowment growth state. ${ }^{12}$ We refer to the counter-cyclical labor income share dispersion as the Mankiw (1986) effect.

Expenditure Ratio The second driving force in the model is the process for the ratio of non-housing to housing expenditures $\{r\}$. Following Piazzesi et al. (2004), we specify an autoregressive process which also depends on aggregate endowment growth $\lambda$ :

$$
\log r_{t+1}=\bar{r}+\rho_{r} \log r_{t}+b_{r} \lambda_{t+1}+\sigma_{r} \nu_{t+1}
$$

\footnotetext{
${ }^{12}$ The one difference with the Storesletten et al. (2004) calibration is that recessions are shorter in our calibration. In their paper the economy is in the low aggregate endowment growth state half of the time. That implies that the unconditional variance of our labor income process is lower.
} 
where $\nu_{t+1}$ is an i.i.d. standard normal process with mean zero, orthogonal to $\lambda_{t+1}$. In our benchmark calibration we set $\rho_{r}=.96, b_{r}=.93$ and $\sigma_{r}=.03$. The parameter values come from estimating equation (16) on US data. ${ }^{13}$ We discretize the process for $\log (r)$ as a fivestate Markov process. A second calibration switches off the effect of consumption growth by setting $b_{r}=0$. Both calibrations fix $\sigma_{r}=.03$. We choose the constant $\bar{r}$ to match the average housing expenditure share of $19 \%$ in the data (NIPA, 1929 to 2004).

Average Housing Collateral Ratio A key quantitative question is whether collateral is sufficiently scarce for our borrowing constraints to have a large effect. Because this question is an important one, we consider two measures to calibrate the average ratio of collateral wealth to total wealth. The first measure focuses on housing collateral, the second measure includes non-housing sources of collateral.

We measure factor payments to housing wealth as total US rental income and factor payments to human wealth as labor income (compensation of employees). NIPA data show that rental income was $3.4 \%$ of rental income plus labor income in 1946-2002 and 4.3\% in 1929-2002. Because the factor payments ratio maps directly into the housing collateral ratio, the data suggest a housing collateral ratio less than $5 \% .^{14}$

To be on the safe side, our second estimate is a broad collateral measure. It includes financial wealth, the market value of the non-farm non-financial corporate sector in the US. We add interest payments and dividend payments to the income stream from collateralizable wealth and we add proprietary income to the income stream from non-collateralizable wealth. The factor payment ratio increases to $8.6 \%$ in the post-war sample and $9.4 \%$ in the full sample (row 2), suggesting a housing collateral ratio less than $10 \%$.

An alternative approach is to compare the collateralizable wealth to income ratio in model and data. Assuming that the expected return on total collateralizable assets is $9 \%$ and the expected dividend growth rate is $3 \%$, then a collateral ratio of $5 \%$ implies a collateral wealth-to-income ratio of $85 \%$ according to Gordon's growth formula: $.85=.05 /(.09-.03)$. Likewise, the implied wealth-to-income ratio is $150 \%$ when the collateral ratio is $10 \%$. In

\footnotetext{
${ }^{13}$ Table 1 in a separate appendix shows regression estimates for $\rho_{r}$ and $b_{r}$.

${ }^{14}$ If $r$ is constant, the housing collateral ratio or the ratio of housing wealth to total wealth is $\frac{1 / r}{1+1 / r}=$ $1 /(1+r)$. This is a very good approximation for the average collateral ratio in the model with stochastic $r$.
} 
US data, the 1929-2004 average ratio of mortgages to income is $55 \%$. If we include financial wealth, that ratio increases to $155 \%$. This approach also points towards a housing collateral ratio of $5 \%$ and a broad collateral ratio of $10 \%{ }^{15}$

Finally, Jorgenson and Fraumeni (1989) estimate human wealth to be $93 \%$ of total wealth, implying a collateral ratio of $7 \%$.

We take the model with a $5 \%$ collateral ratio as our benchmark and consider the economy with a $10 \%$ collateral ratio as an alternative. To simultaneously match the average expenditure share of housing services $(\bar{r})$ of $19 \%$ and the average ratio of housing wealth to total wealth $(m y)$ of $5 \%$ or $10 \%$, we scale up the aggregate non-housing endowment.

Preference Parameters In the benchmark calibration, we use additive utility with discount rate $\delta=.95$, coefficient of relative risk aversion $\gamma=8$, and intratemporal elasticity of substitution between non-housing and housing consumption $\varepsilon=.05$. We fix the relative weight on housing in the utility function $\psi=1$ throughout. ${ }^{16}$ Because our goal is to explain conditional moments of the market return as well as the cross-section of returns, we choose the preference parameters to match key unconditional asset pricing moments for the market return (see section $\mathrm{D}$ of the appendix). We also compute the model for $\gamma \in\{2,5,10\}$ and $\varepsilon \in\{.15, .75\}$. A choice for the parameter $\varepsilon$ implies a choice for the volatility of rental prices:

$$
\sigma\left(\Delta \log \rho_{t+1}\right)=\left|\frac{1}{\varepsilon-1}\right| \sigma\left(\Delta \log r_{t+1}\right)
$$

In NIPA data (1930-2004), the left hand side of (7) is .046 and the right-hand side is .041. The implied $\varepsilon$ is .098. A higher choice for $\varepsilon$ simply implies excessive rental price volatility.

Stock Market Return We define the stock market return as the return on a leveraged claim to the aggregate consumption process $\left\{c_{t}^{a}\right\}$ and denote it by $R^{l}$. In the data, dividends

\footnotetext{
${ }^{15}$ The Gordon growth model is an approximation. Appendix B provides a detailed analysis of this asset value approach to calibrating the collateral share. It reports that the benchmark calibration $(m y=0.05)$ produces a collateral wealth-to-income ratio of $96 \%$. If the average $m y$ were to be calibrated higher, there would have to be a lot more tradeable wealth in the US economy.

${ }^{16}$ The degree of relative risk aversion $\frac{-c u_{c c}}{u_{c}}=\left(\frac{r_{t}}{1+r_{t}}\right) \gamma+\left(\frac{1}{1+r_{t}}\right) \varepsilon^{-1}$ is a linear combination of $\gamma$ and $\varepsilon$ with weights depending on the non-durable expenditure ratio $r_{t}$. In the simulations $r=4.26$ on average, so that the weight on $\gamma$ is .81 on average. Because $r_{t}$ is not very volatile, neither is the degree of risk aversion.
} 
are more volatile than aggregate consumption. We choose leverage parameter $\kappa=3$, where $\sigma\left(\Delta \log d_{t+1}\right)=\kappa \sigma\left(\Delta \log c_{t+1}^{a}\right) .{ }^{17}$ We also price a non-levered claim on the aggregate consumption stream, denoted $R^{c}$. The excess returns, in excess of a risk-free rate, are denoted $R^{l, e}$ and $R^{c, e}$. Table 1 summarizes the benchmark parametrization and the other values we consider in the sensitivity analysis.

[Table 1 about here.]

Computation Our computational strategy is to keep track of cross-sectional distributions over wealth and endowments that change over time. Appendix $\mathrm{C}$ provides the algorithm.

In the next section, we show that our model can explain the US history of equity premia and excess returns when we feed in the actual aggregate consumption growth and collateral shocks that the US economy experienced over the last seven decades.

\section{Time Series Variation in Returns}

In this section, we show that the model captures important features of conditional asset pricing moments: (i) the same return predictability as in the data, and, (ii) highly volatile Sharpe ratios. But first we highlight the model's long-run predictions, using the last seven decades in the US as a testing ground. The value of housing wealth to income shifts dramatically over this period. At the onset of the Great Depression, the mortgage-to-income ratio increases from 25 percent to 50 percent because house prices do not decline as quickly as national income. The ratio subsequently decreases to a minimum of 12 percent by the end of WW-II. After that, the ratio increases almost without interruption to a value of 100 percent today. We focus on three key features of the data: (i) the decline in the volatility of returns and the risk-free rate, (ii) the low-frequency variation in the average risk-free rate, and (iii) the long-run decline in the equity premium since WW-II. Taking as given the observed evolution of the housing collateral ratio, the model replicates all three features.

\footnotetext{
${ }^{17}$ For the period 1930-2004, the volatility of annual nominal dividend growth is $14.8 \%$, whereas the volatility of annual nominal consumption growth (non-durables and services excluding housing services) is $5.6 \%$, a ratio of 2.6 .
} 
Data We use two distinct measures of the housing collateral stock: the value of outstanding home mortgages $(M O)$ and the market value of residential real estate wealth $(R W)$. These time series are from the Historical Statistics for the US (Bureau of the Census) for the period 1889-1945 and from the Flow of Funds (Federal Board of Governors) for 1945-2001. We use both the value of mortgages and the total value of residential wealth to allow for changes in the extent to which housing can be used as a collateral asset. National income is labor income plus net transfer income from the Historical Statistics of the US for 1926-1930 and from the National Income and Product Accounts for 1930-2001. ${ }^{18}$

\subsection{Model Meets Twentieth Century Data}

We feed the observed aggregate consumption growth shocks and the observed housing collateral ratio between 1929 and 2003 into the model. To match the frequency of recessions in the data, we define a recession as a year in which aggregate consumption growth drops one standard deviation below its sample mean. We use two different measures for the collateral ratio: mortgages to national income, $\frac{M O_{t}}{Y_{t}}$, and residential wealth to national income $\frac{R W_{t}}{Y_{t}}$. We equate the percentage deviations of $\left\{\frac{M O_{t}}{Y_{t}}\right\}$ and $\left\{\frac{R W_{t}}{Y_{t}}\right\}$ from their sample average in the data to the percentage deviations of $m y$ in the model by feeding in the right $r_{t}$ process. ${ }^{19}$

Declining Risk Premium and Risk-free Rate Volatility The first panel of Table 2 documents a stunning long-run decrease in the volatilities of excess stock market returns and risk-free rates. The standard deviation of excess stock returns declines from $30 \%$ in the 1930 s to $10 \%$ in the 1990 s, while the standard deviation of the risk-free rate declines from around $7 \%$ to $2 \%$. While inflation was more volatile in the early decades, the volatility of the risk-free rate cannot be accounted for by inflation surprises alone. The second column $\left(\sigma\left(r_{\text {ex-post }}^{f}\right)\right)$ reports annual risk-free rates computed from annualizing the difference between the monthly three-month T-bill rate minus the inflation rate in the same month. The third column subtracts the previous month's inflation rate instead $\left(\sigma\left(r_{\text {ex-ante }}^{f}\right)\right)$. The small

\footnotetext{
${ }^{18}$ The data appendix in Lustig and Van Nieuwerburgh (2005a) provides detailed sources.

${ }^{19}$ The two series $\frac{M O_{t}}{Y_{t}}$ and $\frac{R W_{t}}{Y_{t}}$ are potentially non-stationary. When we use the collateral ratio in regressions, we compute the deviations from a co-integrating relationship between $\log \left(Y_{t}\right) \operatorname{and} \log \left(M O_{t}\right)$, or $\log \left(R W_{t}\right)$. The resulting series are stationary. Details are provided in Lustig and Van Nieuwerburgh (2005a) and the data are downloadable from the authors' web sites.
} 
difference between the two suggests this volatility is not exclusively due to inflation surprises. Most asset pricing models target a stable risk-free rate, but the stability of the risk-free rate is a recent phenomenon. Our model can account for this radical decline in volatility.

[Table 2 about here.]

The model matches the volatility decline in returns. In the benchmark calibration (panel 2 of Figure 2), the standard deviation of the return on an un-levered claim to aggregate consumption declines from $36 \%$ percent in the 1930 s to $12 \%$ in the 1990 s when we use the mortgage-based collateral measure (column 1); it declines from $23 \%$ to $12 \%$ for the residential wealth-based measure (column 3). The model also delivers a steep decline in risk-free rate volatility: from $21 \%$ to $11 \%$ in column 2 and from $16 \%$ to $11 \%$ in column 4 . While this decline is consistent with the data, the model induces too much volatility in the risk-free rate. A modified version of our model with Epstein and Zin (1991)-type preferences solves this problem. ${ }^{20}$ An increase in the intertemporal elasticity of substitution to 0.2 from .125, while keeping the risk aversion coefficient constant at its benchmark value of 8 , allows us to roughly match the volatility. Panel 3 shows that the risk-free volatility now declines from $10 \%$ to $3 \%$, in line with the data. At the same time, this model preserves the steep decline in the stock return volatility: from $29 \%$ to $4 \%$.

Level of the Risk-free Rate The risk-free rate is low when housing collateral is scarce, both in the model and in the data, because the demand for insurance pushes up the price of future consumption. To focus on the long-run dynamics we compute the 9-year moving average of the one-year risk-free rate in the data and in the model. The top row of Figure 3 plots the data, the bottom row plots the model-generated data; the left panel uses the mortgage-based measure and the right panel uses the residential wealth-based measure.

The data reveal a strong positive correlation between the long-run risk-free rate and the housing collateral measure: 0.75 in the left panel and 0.83 in the right panel. The initial increase in housing collateral in the late 1920s coincides with an increase in the risk-free rate. At the start of the 1930s, the risk-free rate declines precipitously and this decline coincides

\footnotetext{
${ }^{20}$ The details of the model with Epstein-Zin preferences are available in a separate appendix.
} 
with a decline in the housing collateral ratio. During WW-II, the federal government did keep real interest rates artificially low. In the post-war period, the two series continue to co-move until the mid-1990s.

The model produces a similar low-frequency pattern for the risk-free rate. The bottom row of Figure 3 shows that the model predicts the decline in the risk-free rate in the Great Depression, the increase in the late 1940s, the decline in the 1960s, the rise in the 1970s, and the decline in the 1980s and early 1990s. Since the mid-1990s, the model predicts an increase in the risk-free rate because housing collateral has become more abundant. One notable divergence is that the increase in housing collateral in the last 10 years did not lead to a commensurate increase in the interest rate. $^{21}$

[Figure 3 about here.]

Equity Premium Finally, our model generates a long-run decline in the equity premium as well as large unexpected return in the 1990s. Many authors have argued that the equity premium has declined substantially over the last four decades. Jagannathan et al. (2000) use Gordon's growth formula to back out the equity premium and conclude it has declined from $8 \%$ in the 1940 s to $1 \%$ in the 1990s. Fama and French (2002) argue that, because of a decrease in the equity premium, capital gains were much higher than expected, especially in the 1990s. Because housing collateral became more abundant since the 1940s, our model delivers this slow decline in the equity premium. In the benchmark economy, the average equity premium $\left(E\left[E_{t}\left[R_{t+1}^{e}\right]\right]\right)$ declines from $10.6 \%$ in the $1940 \mathrm{~s}$ and a high of $11.2 \%$ in the 1960 s to $5.5 \%$ in the 2000 s (first column of Table 3). The model also generates the large unexpected capital gains of the 1990s. The second column reports the sample average of the realized excess return in each decade, $E\left[R_{t+1}^{e}\right]$. The realized return in the $1990 \mathrm{~s}$ is $15.4 \%$, much higher than the equity premium of $7.5 \%$.

[Table 3 about here.]

The decade-by-decade averages somewhat understate the extent of the decline in the equity premium. The left panel on the top row of Figure 4 contrasts the low and the high

\footnotetext{
${ }^{21}$ We conjecture that this may be due to the unprecedented outflow of tradeable wealth from the US in the last decade. This is a topic for future research; the current model abstracts from this.
} 
frequency variation by plotting the model-predicted annual equity premium (dashed line) alongside the 9-year moving-average (solid line). The vertical bars denote recession years. The equity premium is always higher at the onset of a recession. The equity premium peaks at $15 \%$ in the early $1940 \mathrm{~s}$, while it reaches a low of $3.5 \%$ in 2002 . At the same time, the conditional volatility of excess stock returns declines from a high of $25 \%$ in the early 1930 to a low of $15 \%$ in 2002 (left panel on the middle row). Over the same period, the conditional Sharpe ratio declines from .70 to .35 (left panel bottom row).

The predicted variation in conditional excess return moments looks similar to the data. The right panels of figure 4 plot the empirical counterpart to the equity premium, the conditional volatility and the conditional Sharpe ratio of excess returns. To construct these measures, we project realized excess stock return and its realized volatility (constructed from daily data) on the housing collateral measure and the real risk-free rate. Because the housing collateral ratio is slow-moving, we can interpret the projected series as capturing a long-run equity premium and long-run conditional volatility. The conditional Sharpe ratio is the ratio. The equity premium also peaks in the early 1940s around $15 \%$ and declines to $5 \%$ at the end of the sample (top right panel). The conditional volatility also goes from $25 \%$ to $15 \%$ (middle panel), and the Sharpe ratio falls by more than half (bottom panel).

[Figure 4 about here.]

\subsection{Long Horizon Predictability}

If expected returns are vary over time with the housing collateral ratio, then we should find that the housing collateral ratio predicts returns. An important question is whether the model can quantitatively replicate the predictability coefficients found in the data.

Panel 1 of table 4 shows results from predictability regressions of long-horizon excess returns on the lagged housing collateral scarcity measure in the data. ${ }^{22}$ Results are reported

\footnotetext{
${ }^{22}$ Collateral scarcity is measured as $\widetilde{m y}{ }_{t}=\frac{\max \left(m y_{t}\right)-m y_{t}}{\max \left(m y_{t}\right)-\min \left(m y_{t}\right)}$, where $\max \left(m y_{t}\right)$ and $\min \left(m y_{t}\right)$ are the sample maximum and minimum of $\left\{m y_{t}\right\}$. This ratio is always between 0 and 1 . The measure is based on outstanding residential mortgages. Collateral is scarcer when $m y_{t}$ is lower. Details on the computation of $m y_{t}$ are provided in Lustig and Van Nieuwerburgh (2005a) and the data are downloadable from the authors' web sites.
} 
for horizons up to 8 years and for two samples, and are taken from Lustig and Van Nieuwerburgh (2005a). The main findings are that excess returns are higher when collateral is scarce $\left(b_{1}>0\right)$. The effect becomes larger and statistically more significant with the horizon and the $R^{2}$ increases.

Panel 2 shows that the model replicates the pattern of predictability coefficients surprisingly well. It reports regression results inside the model of excess returns on our measure of housing collateral ratio scarcity. When housing collateral is scarce ( $m y$ is low), the excess return is high. The magnitude of the slope coefficients is close to the one we find in the data. Moreover, the $R^{2}$ of the predictability regression increase with the predictability horizon, just as in the data. We find this negative relationship between $m y_{t}$ and the excess return for a non-levered claim, as well as for a levered claim to aggregate consumption $(\kappa=3)$.

[Table 4 about here.]

The predictability literature has identified other variables that predict returns, such as the price-dividend ratio and the risk-free rate. In the data, a lower price-dividend ratio and a lower risk-free rate forecast both higher future returns and higher excess returns. In our model, a lower price-dividend ratio (risk-free rate) forecasts higher (lower) future returns, but lower (higher) future excess returns. This pattern is due to the risk-free rate dynamics. When collateral is scarce, the price of insurance increases, lowering the risk-free rate and pushing up the price-dividend ratio. The theory predicts that the equity premium is high in such periods. Because of the persistence in the housing collateral ratio, future equity premia are also high. This must mean that future realized excess returns are high on average. However, the high excess returns are the result of lower realized returns and even lower future risk-free rates. ${ }^{23}$

Sharpe Ratio in the Data Does our model generate enough volatility in the Sharpe ratio and does the Sharpe ratio co-move correctly with the housing collateral ratio? To evaluate our model against the data, we estimate the Sharpe ratio on annual data from 1927-1992 and compare it to the variation in the Sharpe ratio generated by the model. The

\footnotetext{
${ }^{23}$ Results for the data and model are available upon request.
} 
conditional mean return is the projection of the excess return on the housing collateral ratio, the dividend yield and the ratio of aggregate labor income to consumption, all of which have been shown to forecast annual returns. ${ }^{24}$ Likewise, the conditional volatility is the projection of the standard deviation of intra-year monthly returns on the same predictors. We form the Sharpe ratio as the ratio of the predicted excess returns and predicted volatility. Table 5 shows the estimation results for 1 year returns (column 1), but also for 5 year and 10-year cumulative excess returns (columns 2 and 3). The last three rows of the table indicate the unconditional mean and standard deviation of the Sharpe ratio as well as its correlation with the housing collateral ratio. In the estimation, the correlation between the Sharpe ratio and the measure of collateral scarcity $\widetilde{m y}$ is positive in the data and equal to $.25, .32$, and .50 for 1, 5 and 10 year cumulative excess returns. The volatility of the Sharpe ratio on 1, 5 and 10 year cumulative excess returns is .10, .18, and .20. For quarterly returns (1952-2000), the volatility of the Sharpe ratio is .45 (Lettau and Ludvigson (2003)).

[Table 5 about here.]

Similar to the data, our model generates volatile Sharpe ratios, and Sharpe ratios that co-move correctly with the housing collateral ratio. The correlation between the Sharpe ratio and $\widetilde{m y}$ is also positive: .50, .59 and .39 for 1,5 and 10 year cumulative excess returns on a non-levered consumption claim. The unconditional Sharpe ratio volatility is .40, .42, .40. Other models have a hard time generating this much volatility. For example, the unconditional standard deviation of the Sharpe ratio is .09 for the Campbell and Cochrane (1999) model and the consumption volatility model of Lettau and Ludvigson (2003).

\section{Cross-sectional Variation in Risk Premia}

The second main set of results are about the model's cross-sectional asset pricing implications. Firms with a high ratio of book value to market value of equity (value firms) historically have higher returns than those with a low book-to-market ratio (growth firms).

\footnotetext{
${ }^{24}$ See Lustig and Van Nieuwerburgh (2005a), Lettau and Ludvigson (2001), and Santos and Veronesi (2004) respectively. The data, as well as the measurement of the housing collateral ratio are spelled out in Lustig and Van Nieuwerburgh (2005a).
} 
Panel 1 of Table 6 reports sample means, volatilities, and Sharpe ratios for the excess returns on ten book-to-market deciles. The annual excess return on a zero-cost investment strategy that goes long in the highest book-to-market decile and short in the lowest decile is $6.8 \%$ for 1930-2003 and 6.5\% for 1945-2003. The Sharpe ratios for the highest and lowest decile portfolios are .56 and .37 for $1945-2003$ and .42 and .32 for $1930-2003 .^{25}$

The paper's second main result is that the collateral model can endogenously generate this value premium. We perform two exercises to substantiate this claim. In the first exercise we generate excess returns on value decile portfolios from an empirically plausible factor model. In a second exercise, we impose a specific timing on the cash flows of value and growth portfolios and compute returns on these portfolios.

[Table 6 about here.]

\subsection{Plugging the Empirical Betas into Model}

Value stocks command higher expected returns because their returns co-vary more strongly with aggregate consumption growth when collateral is scarce (Lustig and Van Nieuwerburgh (2005a)). In a first step, we use data on the decile value portfolio returns to describe the return-generating process for each of the book-to-market decile portfolios. We then price these returns inside the model and show that returns on high book-to-market portfolios carry a higher risk premium than returns on low book-to-market portfolios. The return spread in the model matches the spread in the data.

Decile Return Processes in Data To estimate the relationship between excess returns on book-to-market decile portfolios and the model's state variables $(c, r, \widetilde{m y})$, we use data on aggregate consumption growth, expenditure share growth, and the housing collateral ratio and estimate the betas in

$$
\begin{aligned}
R_{t+1}^{e, j}= & \beta_{0}^{j}+\beta_{m y}^{j} \widetilde{m y}_{t+1}+\beta_{c}^{j} \Delta \log c_{t+1}^{a}+\beta_{c, m y}^{j} \widetilde{m y}_{t+1} \Delta \log c_{t+1}^{a}+ \\
& \beta_{r}^{j} \Delta \log r_{t+1}+\beta_{r, m y}^{j} \widetilde{m y} y_{t+1} \Delta \log r_{t+1}+\nu_{t+1}^{j},
\end{aligned}
$$

\footnotetext{
${ }^{25}$ Similar value premia are found for monthly and quarterly returns and for quintile instead of decile portfolios. Using quarterly data for 1951-2002, unconditional Sharpe ratios for value stocks (.64) are twice as large as for growth stocks (.32) (Lettau and Wachter (2005)).
} 
by OLS. The estimates are reported in table 2 of the separate appendix. When collateral is abundant $\left(\widetilde{m y}_{t}=0\right)$, the sensitivity of excess returns to aggregate consumption growth is $\beta_{c}$ (Figure 5, left column). The returns on value stocks (decile 10) are high in recessions while growth stocks (decile 1 ) are much less sensitive to aggregate consumption growth; $\left|\beta_{c}\right|$ increases monotonically from decile 1 to decile 10 . When collateral is scarce $\left(\widetilde{m y}_{t}=1\right)$, the consumption beta is $\beta_{c}+\beta_{c, m y}$ (right column). Value stocks are more sensitive to consumption growth shocks when collateral is scarce: $\beta_{c, m y}>0$ is much higher for the tenth decile than for the first decile portfolio. This sensitivity pattern results in higher expected returns for value stocks than for growth stocks. This effect is reinforced because value stocks are also more sensitive to aggregate expenditure ratio shocks; $\beta_{r}$ increases monotonically for both collateral measures (not shown).

[Figure 5 about here.]

Decile Return Processes in Model In a second step, we generate ten excess return processes as the product of the previously estimated factor loadings $\left(\beta_{m y}^{j}, \beta_{c}^{j}, \beta_{c, m y}^{j}, \beta_{r}^{j}, \beta_{r, m y}^{j}\right)$, and simulated model state variables. For each excess return, the intercept $\beta_{0}^{j}$ is chosen to make the Euler equation hold: $E_{t}\left[m_{t+1} R_{t+1}^{j, e}\right]=0$. This ensures that the model SDF prices the book-to-market decile returns correctly on average. We then simulate the model for 10,000 periods and compute unconditional means and standard deviations of each decile portfolio return.

The second panel of table 6 reports the excess returns on the ten value portfolios predicted by the collateral model, ordered from growth (B1) to value (B10) for the benchmark parametrization. We use two sets of empirical factor loadings corresponding to different housing collateral measures. For the mortgage-based collateral measure, the value spread is $6.8 \%$, matching the data. For the residential wealth measure, the value spread is even larger: 8.4\%. Furthermore, the model predicts that the Sharpe ratio of the tenth decile (value) is double that of the first decile (growth), similar to the post-war data. Figure 2 (in the introduction) plots the return difference between deciles 2-9 and the lowest book-to-market portfolio for the model and for the data. The model does quite well in reproducing these spreads; if anything, the model's spreads are too large. 
Representative Agent Model In the representative agent economy, there are no collateral constraints and perfect risk sharing obtains. This amounts to setting $\widetilde{m y}=0$ in equation (8). The estimated consumption growth and expenditure growth betas exhibit little variation across decile portfolios. The simulated returns that these betas imply, do not generate a value premium, and lower Sharpe ratios on value stocks than on growth stocks, all at odds with the data. ${ }^{26}$

\subsection{Pricing Stocks with Different Duration}

Growth stocks have been described as assets with longer maturities than value stocks (Dechow, Sloan and Soliman (2002) and Lettau and Wachter (2005)). The second approach models growth stocks (value stocks) as a basket of consumption strips that is weighted towards longer (shorter) maturities. A period- $k$ consumption strip is a claim to aggregate consumption $c_{t+k}, k$ years from the current period $t$.

The multiplicative (one year) equity premium $E_{0} R_{0,1}^{e}\left[\left\{c_{k}\right\}\right]$, the expected return on a nonlevered claim to the entire stream of aggregate consumption $\left\{c_{k}\right\}_{k=1}^{\infty}$ divided by the risk-free rate, is a value-weighted sum of expected excess returns on consumption strips:

$$
1+E_{0}\left[R_{0,1}^{e}\left[\left\{c_{k}\right\}\right]\right]=\sum_{k=1}^{\infty} \omega_{k} \frac{E_{0} R_{0,1}\left[c_{k}\right]}{R_{0,1}[1]}, \text { with weights } \omega_{k}=\frac{E_{0} M_{k} c_{k}}{\sum_{l=1}^{\infty} E_{0} M_{l} c_{l}}
$$

The second term in the sum is the (gross) expected return on a period $k$ consumption strip $E_{0} R_{0,1}\left[c_{k}\right]$ divided by the (gross) risk-free rate $R_{0,1}[1]$. The weight $\omega_{k}$ represents the value of the period $k$ consumption strip relative to the total value of all consumption strips. $M_{k}$ is the pricing kernel in period $k$. It is linked to the stochastic discount factor $m$ by $M_{k}=m_{1} \times \cdots \times m_{k}$. (See appendix A for the derivation of equation 9).

We think of value stocks as a claim to a differently weighted stream of aggregate consumption $\left\{f^{v}(k) c_{k}\right\}_{k=1}^{\infty}$, where the function $f(\cdot)$ puts more weight on the consumption realizations in the near future. For example, $f^{v}(k)=C e^{a k}$, where $a$ is a negative number and $C$ is a normalization constant, $C=\frac{\sum_{k=1}^{\infty} c_{k}}{\sum_{k=1}^{\infty} e^{a k} c_{k}}$. Likewise, growth stocks are a claim to a weighted stream of aggregate consumption $\left\{f^{g}(k) c_{k}\right\}_{k=1}^{\infty}$, where $f(\cdot)$ puts more weight on the con-

\footnotetext{
${ }^{26}$ Detailed results available upon request.
} 
sumption realizations in the far future. For example, $f^{g}(k)=C e^{a k}$, where $a$ is a positive number. The multiplicative equity premium $\widetilde{\nu}_{0}$ on such a basket of consumption strips with weights $f(k)$ is:

$$
1+\widetilde{\nu}_{0}=\sum_{k=1}^{\infty} \tilde{\omega}_{k} \frac{E_{0} R_{0,1}\left[c_{k}\right]}{R_{0,1}[1]}, \text { with modified weights } \tilde{\omega}_{k}=\frac{f(k) E_{0} M_{k} c_{k}}{\sum_{l=1}^{\infty} f(l) E_{0} M_{l} c_{l}}
$$

The following proposition shows that the properties of the pricing kernel determine the sign of the value spread. Appendix A proves that, if the pricing kernel has no permanent component, then the highest risk premium is the one on the farthest out consumption strip $(k \rightarrow \infty)$. The model generates a growth premium .

Proposition 1. If $\gamma>1, f(k)=C e^{a k}$ with $a>0$ and if $\lim _{k \rightarrow \infty} \frac{E_{1} M_{k} c_{k}}{E_{0} M_{k} c_{k}}=1$, then $\lim _{a \rightarrow \infty} 1+$ $\widetilde{\nu}_{0}=\lim _{k \rightarrow \infty} R_{0,1}^{e}\left[c_{k}\right] \geq 1+\nu_{0}$, for any sequence of weights $\left\{\omega_{k}\right\}$ in the definition of the multiplicative risk premium $\nu_{0}$.

The proof draws on insights from Alvarez and Jermann (2005). The pricing kernel in our model contains a permanent component stemming from the risk of binding solvency constraints, even in the absence of the consumption growth shocks. ${ }^{27}$ Such a permanent component is a necessary condition for generating a value premium.

Representative Agent Economy In the representative agent economy, the equity premia on consumption strips do not change with the horizon. This is easy to show for additive preferences that are separable in both commodities and aggregate endowment growth that is i.i.d with mean $\bar{\lambda}{ }^{28}$ The pricing kernel is simply a function of the aggregate consumption growth rate between period 1 and period $k: M_{k}=\lambda_{k}^{-\gamma} \lambda_{k-1}^{-\gamma} \cdots \lambda_{1}^{-\gamma}$. Because the aggregate endowment grows every period at the rate $\lambda, M_{1} c_{1}=\lambda_{1}^{-\gamma} \lambda_{1} c_{0}$. For the period $k$ strip, $M_{k} c_{k}=\lambda_{k}^{1-\gamma} \lambda_{k-1}^{1-\gamma} \cdots \lambda_{1}^{1-\gamma} c_{0}$. Hence, the expected return on a period $k$ strip is:

$$
E_{0} R_{0,1}\left[c_{k}\right]=\frac{E_{1}\left(M_{k} c_{k}\right)}{E_{0}\left(M_{k} c_{k}\right)}=\frac{E_{1}\left(\lambda_{k}^{1-\gamma} \lambda_{k-1}^{1-\gamma} \cdots \lambda_{1}^{1-\gamma} c_{0}\right)}{E_{0}\left(\lambda_{k}^{1-\gamma} \lambda_{k-1}^{1-\gamma} \cdots \lambda_{1}^{1-\gamma} c_{0}\right)}=\left(\frac{\lambda_{1}}{\bar{\lambda}}\right)^{1-\gamma}
$$

\footnotetext{
${ }^{27}$ Section 5 explains that the aggregate weight shock, which measures the extent of binding solvency constraints and enters as a multiplicative term in the SDF, is a non-decreasing stochastic process.

${ }^{28} \mathrm{~A}$ similar result obtains if preferences are non-separable and aggregate expenditure share growth is i.i.d., even when aggregate expenditure share growth is correlated with aggregate consumption growth.
} 
The expression does not depend on the horizon $k$, meaning that strip risk premia are constant across horizons. Since the term structure of consumption risk premia is flat, the value premium is zero.

Term Structure of Strip Premia and Time-Varying Value Premia Our model behaves like a representative agent economy when housing collateral is abundant. These are times when the term structure of risk premia is nearly flat. However, collateral scarcity generates a downward sloping term structure of risk premia. Since the model oscillates between abundant collateral (flat term structure) and scarce collateral (downward sloping term structure), it generates a downward slope on average. This generates a value premium, because value stocks load more heavily on short duration consumption strips. Put differently, because short term assets are more risky than long term assets, the expected return and Sharpe ratio are higher for value stocks than growth stocks.

The downward sloping term structure relies crucially on having two model driving forces that operate at different horizons: changes in aggregate consumption growth, which cause shocks to the wealth distribution, at business cycle frequencies and changes to the collateral ratio at low frequencies. Risk premia on long-maturity assets respond mostly to lowfrequency collateral changes, whereas short-maturity assets respond to both shocks. Suppose that collateral is scarce and there is a negative aggregate consumption growth shock (a recession). This shock resolves risk, because it lowers the likelihood of being constrained in the immediate future (the left tail of the wealth distribution is 'cleansed'). The risk premium decreases. But the risk-free rate increases by more so that the discount rate increases. Higher discount rates imply lower prices. But because the aggregate consumption growth shock is temporary, it only lowers the price of short-maturity assets and not the price of long-maturity assets. In section 5, we will be more explicit about the wealth distribution dynamics that drive this.

Prices and expected returns are inversely related, so that the term structure of expected returns is downward sloping. Put differently, expected returns on value stocks increase because short-duration assets have higher consumption growth risk when collateral is scarce. For long-duration assets such as growth stocks, only long-term discount rates matter. These 
are governed by the housing collateral ratio and not by aggregate consumption growth.

If there is only one driving force, as in the habit formation model, a fall in aggregate consumption increases marginal utility growth not just today, but persistently into the future. Therefore, it generates a bigger price decline of long-duration consumption strips than of short-duration strips. The term structure of risk premia is upward sloping. The habit model predicts a growth premium (Lettau and Wachter (2005)).

Panels 1 and 2 of Figure 6 plot the expected return and Sharpe ratio on consumption strips of horizons of 1 to 45 years for the benchmark model. Long-maturity strips have risk premia and Sharpe ratios that are lower than those for short-maturity strips. This pattern can be traced back to their differential consumption risk.

[Figure 6 about here.]

Finally, panel 3 of Table 6 reports equity premia on claims to $\left\{C e^{a k} c_{k}\right\}$. These are baskets of consumption strips of different maturities, where the constant $a$ governs the duration of the basket. The leverage parameter $\kappa$ is 2 . We vary $a$ from .5 to -.5. The corresponding baskets have a duration between 43 years and 2 years (row 1). We think of the baskets with long-duration as the growth portfolios and the baskets with short-duration as the value portfolios (Dechow et al. (2002)). The benchmark model generates a maximum value spread of $5.2 \%$ between the 8 -year and the 43 -year portfolios, close to the value spread in the data. In addition, the Sharpe ratios on the value portfolios are much higher than the Sharpe ratios on the growth portfolios. The bottom row of Figure 6 confirms that long-duration assets (growth stocks) have lower risk premia and lower Sharpe ratios.

To summarize, when confronted with the actual aggregate consumption growth shocks and the actual housing collateral ratio, the model delivers the same low frequency changes in the level and volatility of the equity premium and the risk-free rate that we document in the data. It generates the same predictability patterns and volatile Sharpe ratios as in the data. In addition, the model matches the cross-sectional variation in risk premia on bookto-market sorted stocks. The last section explains in detail how movements in the housing collateral ratio induce variation in Sharpe ratios. This section can be skipped by readers mainly interested in the asset pricing results. 


\section{Inside the Model}

This section explains the model's equilibrium dynamics in detail. To characterize the equilibrium consumption dynamics and link these to the state prices of consumption, we use stochastic consumption weights.

\subsection{Equilibrium Consumption Dynamics and the Collateral Ratio}

We use a simple risk-sharing rule to characterize the equilibrium consumption choices for each household in an equivalent time zero trading environment. ${ }^{29}$

Let $\xi_{t}\left(\ell, s^{t}\right)$ be the cumulative Lagrange multiplier on the collateral constraint (4) at time $t$ for household $\left(\ell, s_{0}\right)$. When the constraint does not bind, its Lagrange multiplier is zero, and the household's cumulative multiplier remains unchanged. But when the constraint binds, the multiplier increases to a cutoff level $\underline{\xi}_{t}\left(y_{t}, z^{t}\right)$. This cutoff is the consumption share at which the collateral constraint holds with equality. Note that the cutoff only depends on the current event $y_{t}$, not on the entire history. Summarizing the dynamics:

$$
\xi_{t}\left(\ell, y^{t}, z^{t}\right)= \begin{cases}\xi_{t-1}\left(\ell, s^{t-1}\right) & \text { if } \xi_{t-1}\left(\ell, s^{t-1}\right)>\underline{\xi}_{t}\left(y_{t}, z^{t}\right) \\ \underline{\xi}_{t}\left(y_{t}, z^{t}\right) & \text { if } \xi_{t-1}\left(\ell, s^{t-1}\right) \leq \underline{\xi}_{t}\left(y_{t}, z^{t}\right)\end{cases}
$$

The aggregate weight process $\xi_{t}^{a}\left(z^{t}\right)$ summarizes to what extent collateral constraints bind on average, i.e. across households:

$$
\xi_{t}^{a}\left(z^{t}\right)=\sum_{y^{t}} \int \xi_{t}^{\frac{1}{\gamma}}\left(\ell, y^{t}, z^{t}\right) d \mathcal{L}_{0} \frac{\pi\left(y^{t}, z^{t} \mid y_{0}, z_{0}\right)}{\pi\left(z^{t} \mid z_{0}\right)}
$$

Household $\left(\ell, s^{t}\right)^{\prime}$ 's consumption shares $\frac{c_{t}\left(\ell, s^{t}\right)}{c_{t}^{a}}$ and $\frac{h_{t}\left(\ell, s^{t}\right)}{h_{t}^{a}}$ are completely determined by the ratio $\frac{\xi_{t}\left(\ell, s^{t}\right)^{\frac{1}{\gamma}}}{\xi_{t}^{a}\left(z^{t}\right)}$. This ratio captures the household's position in the wealth distribution.

$$
c_{t}\left(\ell, s^{t}\right)=\frac{\xi_{t}\left(\ell, s^{t}\right)^{\frac{1}{\gamma}}}{\xi_{t}^{a}\left(z^{t}\right)} c_{t}^{a}\left(z^{t}\right) \text { and } h_{t}\left(\ell, s^{t}\right)=\frac{\xi_{t}\left(\ell, s^{t}\right)^{\frac{1}{\gamma}}}{\xi_{t}^{a}\left(z^{t}\right)} h_{t}^{a}\left(z^{t}\right)
$$

\footnotetext{
${ }^{29}$ A separate appendix derives the equivalence of equilibria in these two trading environments if interest rates are high enough in the sense of Alvarez and Jermann (2000).
} 
We verify in a separately available appendix that this rule satisfies the first order condition for non-housing and housing consumption and the market clearing conditions. Combining (11) and (10), when a household switches to a state with a binding constraint, its consumption share increases. Everywhere else, its consumption share is drifting downwards at the rate $\frac{\xi_{t+1}^{a}}{\xi_{t}^{a}}$. Shocks to $\xi_{t}^{a}\left(z^{t}\right)$ reflect aggregate shocks to the wealth distribution. Because they follow from an inability to insure against human wealth shocks, these can be interpreted as liquidity shocks.

Combining the risk-sharing rule (11) for unconstrained households $\left(\xi_{t+1}\left(\ell, s^{t+1}\right)=\xi_{t}\left(\ell, s^{t}\right)\right)$ and (5), we obtain a new expression for the SDF:

$$
m_{t+1}=\delta\left(\frac{c_{t+1}^{a}}{c_{t}^{a}}\right)^{-\gamma}\left(\frac{1+r_{t+1}^{-1}}{1+r_{t}^{-1}}\right)^{\frac{1-\varepsilon \gamma}{\varepsilon-1}}\left(\frac{\xi_{t+1}^{a}}{\xi_{t}^{a}}\right)^{\gamma}
$$

For future reference, we denote the equilibrium price of a claim to some payoff stream $\{d\}$ in units of $z^{t}$ consumption as

$$
\Pi_{z^{t}}[\{d\}]=\sum_{k=1}^{\infty}\left(\prod_{j=1}^{k} M_{t, t+j}\left(z^{t+j}\right) \pi\left(z^{t+j} \mid z_{t}\right)\right) d_{t+k}
$$

where $M_{t, t+j}=m_{t+1} m_{t+2} \ldots m_{t+j}$ is the $j$-period ahead pricing kernel.

A Benchmark Economy The perfect commitment environment provides a useful benchmark for understanding asset prices. Because households are never constrained, the individual multiplier stays constant at its initial value: $\xi_{t}\left(\ell, s^{t}\right)=\xi_{0}\left(\ell, s_{0}\right)$. The aggregate weight process reflects the initial wealth distribution and is constant: $\xi_{t}^{a}\left(z^{t}\right)=\xi_{0}^{a}\left(z_{0}\right)=$ $\int \xi_{0}\left(\ell, s_{0}\right)^{\frac{1}{\gamma}} d \Phi_{0}\left(z_{0}\right) .{ }^{30}$ Consumption shares are constant, consumption levels only move with aggregate consumption and there is full insurance. All agents equate their IMRS and the SDF is the standard Breeden-Lucas pricing kernel, adjusted for a composition factor that arises from the non-separability between non-housing and housing consumption. It contains only the first two factors in (12).

\footnotetext{
$\mathcal{L}_{0}$.

${ }^{30} \Phi_{0}$ is the initial distribution of multipliers $\xi_{0}$, a monotone transformation of the initial wealth distribution
} 
A Multiplicative Discount Factor Adjustment The third term in (12) is the growth rate of the aggregate consumption weight process $\xi_{t+1}^{a}$, raised to the power of risk aversion $\gamma$. It reflects the departure from full commitment and measures the risk of binding solvency constraints. When many households are severely constrained in state $z^{t+1}\left(\xi^{a}\left(z^{t+1}\right)>\xi^{a}\left(z^{t}\right)\right)$, the price of consumption in that state is high, because the unconstrained households experience high marginal utility growth: When lots of households run into binding constraints and experience consumption share increases, the unconstrained households have to experience large decreases in their consumption shares. The increase in the price of consumption induces them to accept low consumption growth rates. When nobody is constrained, the aggregate consumption weight process stays constant, $\xi^{a}\left(z^{t+1}\right)=\xi^{a}\left(z^{t}\right)$, and the representative agent SDF re-emerges. The risk of binding solvency constraints endogenously creates heteroscedasticity in the SDF.

Housing Collateral The novel feature of this model is that the tightness of the constraints, and therefore the size of the multiplicative adjustment to the SDF, depends on the ratio of aggregate housing wealth to aggregate total wealth, $m y\left(z^{t}\right)$ :

$$
m y\left(z^{t}\right)=\frac{\Pi_{z^{t}}\left[\left\{h^{a} \rho\right\}\right]}{\Pi_{z^{t}}\left[\left\{c^{a}+h^{a} \rho\right\}\right]}=\frac{\Pi_{z^{t}}\left[\left\{c^{a} r^{-1}\right\}\right]}{\Pi_{z^{t}}\left[\left\{c^{a}\left(1+r^{-1}\right)\right\}\right]} .
$$

The numerator measures the value of collateralizable wealth; it equals the price of a claim to the aggregate housing dividend. The denominator is the sum of collateralizable housing wealth and non-collateralizable human wealth. If the expenditure ratio $r$ is constant, the collateral ratio equals $\frac{1}{1+r}$. If $r$ varies over time in a persistent manner, then the housing collateral ratio $m y$ inherits this persistent variation. This variation in the collateral ratio affects $\frac{\xi_{t+1}^{a}}{\xi_{t}^{a}}$ and therefore the amount of risk sharing that can be sustained and equilibrium asset prices. We formalize this in the following two propositions, proven in appendix A.

If the total housing claim is sufficiently valuable, then perfect risk sharing can be sustained.

Proposition 2. Let $\Pi^{*}[\{\cdot\}]$ denote the price of that claim under perfect risk-sharing and let 
$r=r_{\text {max }}$ denote the maximum expenditure ratio. Perfect risk sharing can be sustained if

$$
\Pi_{z}^{*}\left[\left\{c^{a}(z)\left(1+r_{\max }^{-1}\right)\right\}\right] \geq \Pi_{z, y}^{*}[\{\eta(y, z)\}] \text { for all }(y, z) \in Y \times Z
$$

This condition guarantees that each household can consume the average endowment without violating its collateral constraint. The following proposition states that an economy with more housing collateral (lower $r$ ) has lower cutoffs $\underline{\xi}$, thereby allowing for more consumption smoothing. Such an increase in the supply of collateral brings the cutoff consumption share closer to its lower bound of zero. In the limit perfect risk-sharing obtains. Conversely, a decrease in the supply of collateral (higher $r$ ) brings the cutoff rules closer to their upper bound, the labor income shares $\hat{\eta}$. In the limit, as the collateral disappears, the economy reverts to autarky (no risk sharing).

Proposition 3. Assume utility is separable and consider two economies, denoted by superscripts 1 and 2. If $r_{\tau}^{1}\left(z^{\tau}\right)<r_{\tau}^{2}\left(z^{\tau}\right), \forall z^{\tau} \geq z^{t}$ then the cutoffs satisfy $\underline{\xi}^{1}\left(y_{t}, z^{t}\right) \leq \underline{\xi}^{2}\left(y_{t}, z^{t}\right)$. As $r_{\tau}\left(z^{\tau}\right) \rightarrow \infty$ for all $z^{\tau} \geq z^{t}, \underline{\xi}\left(y_{t}, z^{t}\right) \rightarrow \hat{\eta}\left(y_{t}, z^{t}\right)$. Conversely, as $r_{\tau}\left(z^{\tau}\right) \rightarrow 0$ for all $z^{\tau} \geq z^{t}$, $\underline{\xi}\left(y_{t}, z^{t}\right) \rightarrow 0$.

Differences in the $r$ process affect the equilibrium aggregate multiplier process $\xi^{a}$. An economy with a uniformly lower housing collateral (higher $r$ ) process has higher liquidity shocks and lower average interest rates (or equivalently higher average state prices):

Corollary 1. Assume utility is separable and consider two economies, 1 and 2. Fix the distribution of initial multipliers across economies: $\Phi_{0}^{1}\left(z_{0}\right)=\Phi_{0}^{2}\left(z_{0}\right)$. If $r_{t}^{1}\left(z^{t}\right)<r_{t}^{2}\left(z^{t}\right), \forall z^{t}$ then $\left\{\xi_{t}^{a, 1}\left(z^{t}\right)\right\} \leq\left\{\xi_{t}^{a, 2}\left(z^{t}\right)\right\}$, and the state prices are higher on average in the second economy.

The last proposition and corollary compare two economies with different collateral processes $\{r\}$ to illustrate the mechanism that underlies time-variation in the market price of risk.

Computation These aggregate weight shocks play a key role in the numerical computation of equilibria. To solve the model numerically, we rely on an approximation of the growth rate of the aggregate weight shock $g_{t}\left(z^{t}\right) \equiv \frac{\xi_{t}^{a}\left(z^{t}\right)}{\xi_{t-1}^{a}\left(z^{t-1}\right)}$ using a truncated history of aggregate shocks. This is discussed in detail in appendix C. 


\subsection{Two Driving Forces}

To build intuition for the asset price results, we first explain the two main driving forces of the model: shocks to the wealth distribution, operating at business cycle frequencies, and variation in the housing collateral ratio, operating at low frequencies. Both of these forces affect the SDF $m_{t+1}$ in (12) through its third term $g_{t+1}^{\gamma}$, which is a function of the aggregate weight shock $g_{t+1}=\frac{\xi_{t+1}^{a}}{\xi_{t}^{a}}$.

Shocks to the Wealth Distribution Because risk sharing is imperfect, the higher crosssectional income dispersion in a low aggregate consumption growth state results in more wealth and consumption dispersion. First, the household cutoff levels are higher in low aggregate consumption growth states, $\underline{\xi}\left(y_{t}, z^{t-1}, r e\right)>\underline{\xi}\left(y_{t}, z^{t-1}, e x\right)$, and this makes the consumption increase for households that switch to a state with a binding constraint larger. Second, low aggregate consumption growth states are short-lived in our model and agents are more constrained in these states as a result, because of their desire to smooth out its effect on their consumption. As the combined result of these two forces, the size of the aggregate weight shock increases more in low aggregate consumption growth states $\left(g_{t+1}\left(z^{t}, r e\right)>g_{t+1}\left(z^{t}, e x\right)\right)$. However, after a low consumption growth shock accompanied by a large aggregate weight shock $g_{t+1}$, the left tail of the wealth distribution is cleansed, and subsequent aggregate weight shocks are much smaller. This cleansing mechanism lowers the conditional market price of risk $\sigma_{t}\left[m_{t+1} / E_{t}\left[m_{t+1}\right]\right.$ and increases the interest rate after a bad shock. These wealth distribution dynamics operate at business cycle frequencies and are also present in Lustig (2003). They are a first source of heteroscedasticity in the SDF.

Housing Collateral Mechanism There is another source of heteroscedasticity: low frequency changes in the housing collateral ratio. This paper's novel feature are movements in the housing collateral ratio that come from exogenous movement in the non-housing expenditure ratio $r$ together with endogenous movements in the SDF (equation 13).

Figure 7 illustrates the collateral mechanism for a typical two hundred period simulation of the benchmark model. Panel 1 plots the housing collateral ratio my (bold, right axis) together with the expenditure ratio $r$ (single line, left axis). It shows that the housing collateral 
ratio increases when households spend a larger share of income on housing. The persistence of $m y$ comes from this relationship. Panel 2 plots the cross-sectional consumption growth dispersion (single line, left axis) against the housing collateral ratio my (bold line, right axis). It summarizes the risk sharing dynamics in the model. When collateral is scarce, more households run into binding collateral constraints. To prevent default, the consumption share of the constrained households increases. At the same time, the unconstrained households' consumption share decreases precipitously (see equation 11). As a result, the cross-sectional standard deviation of consumption growth increases, evidence of less risk-sharing. For example, in a period of collateral abundance (period 126), $\sigma_{t}\left[\Delta \log c_{t+1}\right]$ is $8.1 \%$, whereas in a period of collateral scarcity (period 174), it is only $0.9 \%{ }^{31}$ The aggregate weight shock $g_{t+1}$, plotted in panel 3, measures the economy-wide extent to which the solvency constraints bind. It also governs the new component to the SDF $g_{t+1}^{\gamma}$. The panel illustrates that when collateral is scarce, constraints bind more frequently and more severely and this is reflected in a large aggregate weight shock. For example, in period 126 the liquidity shock is 1.07 , whereas in period 174 it is only 1.01. The SDF is higher and more volatile in such periods of collateral scarcity, and quite different from the representative agent SDF. The next panels illustrate how this impacts asset prices.

[Figure 7 about here.]

Equity premium The fourth panel of figure 7 shows that the conditional expected excess return on a non-levered claim to aggregate consumption $E_{t}\left[R_{t+1}^{c, e}\right]$ (dotted line, left axis) is higher in periods of collateral scarcity (full line right axis). The conditional equity premium is $13.5 \%$ when $m y$ is low (period 126), but only $4.5 \%$ when the housing collateral ratio is high (period 174). The fifth panel shows that the conditional volatility of the excess return on the consumption claim (left axis) is $10.3 \%$ when collateral is abundant (period 174) and more than doubles to $24 \%$ when collateral is scarce (period 126). The net result of the collateral mechanism is a conditional Sharpe ratio $\left(E_{t}\left[R_{t+1}^{c, e}\right] / \sigma_{t}\left[R_{t+1}^{c, e}\right]\right)$ that is higher in times

\footnotetext{
${ }^{31}$ As an aside, even though the consumption shares change in important ways when collateral constraints bind, the unconditional volatility of consumption growth for an individual household is moderate. In our benchmark model it is less than $10 \%$ of the unconditional volatility of individual income growth. There is still a considerable amount of risk-sharing.
} 
of collateral scarcity (sixth panel). It is .34 in period 174 and almost .57 in period 126 .

Figure 8 summarizes the conditional asset pricing moments somewhat differently. It plots the averages of these conditional asset pricing moments against the value of the collateral ratio. The entire time-series of conditional asset pricing moments is computed, then averaged over histories of the aggregate state $\left(z_{t-1}, \cdots, z_{t-k}\right)$, sorted according to whether the last aggregate shock realization $z_{t}$ was high (dashed line) or low (full line), and then sorted according to $m y$. The first row of the figure replicates figure 1, except that it discriminates between whether the current realization of the aggregate state is high or low. Concentrating on the dashed lines, the equity premium is $9 \%$ higher when collateral is scarce $(m y=.04)$ than when it is abundant $(m y=.10)$ in the first panel. The other two panels in the top row match our earlier findings of higher conditional volatility and Sharpe ratios when collateral is scarce. ${ }^{32}$ The bottom row shows that the conditional market price of risk $\sigma_{t}\left[m_{t+1}\right] / E_{t}\left[m_{t+1}\right]$, an upper bound on the Sharpe ratio, is higher when collateral is scarce (panel 4). The price-dividend ratio in panel 5 is also higher when collateral is scarce because the demand for insurance against binding solvency constraints drives up the price of stocks. It also drives up the price of bonds. So, the model simultaneously generates a high equity premium and a high price-dividend ratio because the risk-free rate is low when collateral is scarce (panel 6).

[Figure 8 about here.]

These are the dynamics of asset prices that underly our main results in sections 3 and 4 .

\subsection{Unconditional Asset Pricing Moments}

Finally, Appendix D discusses the model's unconditional asset pricing moments. The model matches the mean equity premium and its volatility, the mean Sharpe ratio, and the mean risk-free rate for the benchmark parametrization. A representative agent economy is unable to deliver these results, even if preferences are non-separable between housing and nonhousing consumption. Our model has one major drawback: it generates too much volatility in the risk-free rate. We show that an increase in the elasticity of intertemporal substitution

\footnotetext{
${ }^{32}$ The slight non-monotonicity for low collateral ratios comes from the Chebychev approximation used to compute policy functions.
} 
goes a long way towards mitigating this problem. Furthermore, the lower volatility of the risk-free rate in the post-war era masks an important, and often overlooked stylized fact: The volatility of the risk-free rate has changed substantially from decade to decade in the US. We argued in section 3 that this is not simply a measurement issue due to changes in inflation volatility, and we showed that our model is consistent with this long-run decline in risk-free rate volatility.

\section{Conclusion}

Our paper shows how endogenous, state-contingent borrowing constraints interact with shocks in the housing market to deliver plausible asset pricing predictions. Equilibrium changes in the value of the housing stock change the degree to which risk sharing takes place, and modify households' ability to commit to allocations and prices. For a plausibly calibrated housing collateral process, we significantly improve on the predictions of the canonical consumption-based asset pricing model along three dimensions: time-series variation in conditional asset pricing moments, cross-sectional variation in returns, and unconditional asset pricing moments. The housing collateral mechanism, in combination with the wealth distribution shocks, endogenously generate time-varying volatility in the Sharpe ratio on equity, whereas in other models this feature is built into the preferences or the consumption dynamics.

In a recent paper, Daniel and Titman (2005) question the success of a string of recent (conditional) CCAPM papers in explaining the cross-section of size and value returns. Their point is that one only needs two factors to explain returns along the two risk dimensions size and value. What is needed then to tell the models apart is more over-identifying restrictions (more asset pricing moments), and other (non-asset pricing) evidence. We have taken the second route in other work. In this paper, we chose the first route. We have tried to match not only the cross-section of risk premia, but also the time-variation in returns on equity and debt, not only at business-cycle frequencies, but also at lower frequencies. 


\section{References}

Abel, Andrew, "Asset Prices under Habit Formation and Catching Up with the Joneses," American Economic Review, 1990, 80, 38-42.

Abel, Andrew B., "Risk Premia and Term Premia in General Equilibrium," Journal of Monetary Economics, 1999, 43, 3-33.

Alvarez, Fernando and Urban Jermann, "Efficiency, Equilibrium, and Asset Pricing with Risk of Default.," Econometrica, 2000, 68 (4), 775-798.

and __ , "Quantitative Asset Pricing Implications of Endogenous Solvency Constraints,", Review of Financial Studies, 2001, 14, 1117-1152.

and _ _ "Using Asset Prices to Measure the Persistence of the Marginal Utility of Wealth," Econometrica, 2005, 73(6), 1977 -2016.

Atkeson, Andrew and Robert E. Lucas, "On Efficient Distribution with Private Information," Review of Economic Studies, 1993, 59, 427-453.

Bansal, Ravi and Amir Yaron, "Risks for the Long Run: A Potential Resolution of Asset Prizing Puzzles," The Journal of Finance, August 2004, 59, 1481-1509.

Bekaert, Geert, Eric Engstrom, and Steven Grenadier, "Stock and Bond Returns with Moody Investors," 2004. Working Paper Columbia University.

Breeden, Douglas T., "An Intertemporal Asset Pricing Model with Stochastic Consumption and Investment Opportunities," Journal of Financial Economics, 1979, 7, 265-296.

Campbell, John Y. and John H. Cochrane, "By Force of Habit: A Consumption-Based Explanation of Aggregate Stock Market Behavior.," Journal of Political Economy, 1999, $107(2), 205-251$.

and Robert J. Shiller, "The Dividend-Price Ratio and Expectations of Future Dividends and Discount Factors," Review of Financial Studies, 1988, 1, 195-228. 
Cochrane, John H., "Explaining the Variance of Price-Dividend Ratios," Review of Financial Studies, june 1991, 5 (2), 243-280.

, Asset Pricing, Princeton, N.J.: Princeton University Press, 2001.

Constantinides, George M., "Habit-formation: A Resolution of the Equity Premium Puzzle," Journal of Political Economy, 1990, 98, 519-543.

Daniel, Kent and Sheridan Titman, "Testing Factor Market Explanations of Market Anomalies," July 2005. Northwestern University and UT Austin.

Dechow, Patricia M., Richard G. Sloan, and Mark T. Soliman, "Implied Equity Duration: A New Measure of Equity Risk," December 2002. Stanford University Working paper.

Dunn, K. and K. Singleton, "Modeling the Term Structure of Interest Rates Under Nonseparable Utility and Durability of Goods," Journal of Financial Economics, 1986, 17, 769-799.

Eichenbaum, Martin and Lars Peter Hansen, "Estimating Models with Intertemporal Substitution Using Aggregate Time Series Data," Journal of Business and Economic Statistics, 1990, 8 (1), 53-69.

Epstein, L. and S. Zin, "Substitution, Risk Aversion and the Temporal Behavior of Consumption and Asset Returns," Journal of Political Economy, 1991, 99(6), 263-286.

Fama, Eugene F. and Kenneth R. French, "Dividend Yields and Expected Stock Returns," Journal of Financial Economics, 1988, 22, 3-27.

and __ , "The Cross-Section of Expected Stock Returns," Journal of Finance, 1992, $47(2), 427-465$.

__ and _ _ "The Equity Premium," Journal of Finance, 2002, 57, 637-659.

Ferson, Wayne E. and Campbell R. Harvey, "The Variation of Economic Risk Premiums," Journal of Political Economy, 1991, 99, 385-415. 
and George M. Constantinides, "Habit Persistence and Durability in Aggregate Consumption," Journal of Financial Economics, 1991, 29, 199-240.

Flavin, Marjorie, "Owner-Occupied Housing in the Presence of Adjustment Costs: Implications for Asset Pricing and Nondurable Consumption," October 2001. Mimeo UCSD.

Geanakoplos, John and William Zame, "Collateral, Default, and Market Crashes," 2000. Working paper Yale University.

Goetzman, William N. and Philippe Jorion, "Testing the Predictive Power of Dividend Yields," Journal of Finance, 1993, 48, 663-679.

Hodrick, Robert, "Dividend Yields and Expected Stock Returns: Alternative Procedures for Inference and Measurement," Review of Financial Studies, 1992, 5, 357-386.

Jagannathan, Ravi, Ellen McGrattan, and Anna Scherbina, "The Declining US Equity Premium," Federal Reserve Bank of Minneapolis Quarterly Review, 2000, 24(4), Fall 2004, 3-19.

Jorgenson, Dale M. and B.M Fraumeni, "The Accumulution of Human and NonHuman Capital," in R.E. Lipsey and H.S Tice, eds., The Measurement of Saving, Investment and Wealth, University of Chicago: University of Chicago press, 1989, pp. 227 282.

Kehoe, Patrick J. and Fabrizio Perri, "International Business Cycles with Endogenous Incomplete Markets," Econometrica, May 2002, 70 (3), 907-928.

Kehoe, Timothy and David Levine, "Debt-Constrained Asset Markets.," Review of Economic Studies, 1993, 60, 865-888.

Kreps, David and E. L. Porteus, "Temporal Resolution of Uncertainty and Dynamic Choice Theory," Econometrica, 1978, 46, 185-200.

Krueger, Dirk, "Risk Sharing in Economies with Incomplete Markets," June 2000. mimeo. and Fabrizio Perri, "Does Income Inequality Lead to Consumption Inequality? Evidence and Theory.," Review of Economic Studies, 2005. Forthcoming. 
Kubler, Felix and Karl Schmedders, "Stationary Equilibria in Asset-Pricing Models with Incomplete Markets and Collateral," Econometrica, 2003, 71, 1767-1795.

Lamont, Owen, "Earnings and Expected Returns," Journal of Finance, October 1998, 53, $1563-1587$.

Lettau, Martin and Jessica Wachter, "Duration of Equity and the Failure of the CAPM," 2005. forthcoming Journal of Finance.

and Stijn Van Nieuwerburgh, "Reconciling the Return Predictability Evidence: InSample Forecasts, Out-of-Sample Forecasts, and Parameter Instability," 2005. Working Paper Stern School of Business.

and Sydney Ludvigson, "Measuring and Modeling Variation in the Risk-Return Tradeoff," March 2003. New York University Working Paper.

— and Syndey Ludvigson, "Consumption, Aggregate Wealth and Expected Stock Returns," The Journal of Finance, June 2001, 56 (3), 815-849.

_ Sydney Ludvigson, and Jessica Wachter, "The Declining Equity Premium: What Role Does Macroeconomic Risk Play?," Working paper, 2005.

Ljungqvist, Lars and Harald Uhlig, "Tax Policy and Aggregate Demand Management Under Catching Up With the Joneses," American Economic Review, 2000, 90 (3), 356366.

_ and Thomas J. Sargent, Recursive Macroeconomic Theory, First Edition, Cambridge, Mass.: MIT Press, 2000.

Lucas, Robert, "Asset Prices in an Exchange Economy," Econometrica, 1978, 46 (6), 1429-54.

Lustig, Hanno, "The Wealth Distribution and Aggregate Risk," 2003. Mimeo University of Chicago.

and Stijn Van Nieuwerburgh, "Housing Collateral, Consumption Insurance and Risk Premia: An Empirical Perspective," Journal of Finance, 2005, 60 (3), 1167-1219. 
and , "How Much Does Housing Collateral Constrain Regional Risk Sharing," August 2005. Working Paper NYU Stern and UCLA.

_ and _ _ , "The Returns on Human Capital: Good News on Wall Street is Bad News on Main Street," Working Paper UCLA and NYU Stern, 2005.

Mankiw, Gregory N., "The Equity Premium and the Concentration of Aggregate Shocks," Journal of Financial Economics, 1986, 17, 211-219.

Marcet, Albert and Ramon Marimon, "Recursive Contracts," 1999. working paper Universitat Pompeu Fabra.

Mehra and Edward Prescott, "The Equity Premium: A Puzzle.," Journal of Monetary Economics, 1985, 15 (2), 145-161.

Menzly, Lior, Tano Santos, and Pietro Veronesi, "Understanding Predictability," Journal of Political Economy, February 2004, 112 (1), 1-47.

Piazzesi, Monika, Martin Schneider, and Selale Tuzel, "Housing, Consumption and Asset Pricing," January 2004. working paper UCLA.

Santos, Tano and Pietro Veronesi, "Labor Income and Predictable Stock Returns," Review of Financial Studies, 2004, forthcoming.

Sargent, Thomas J., Dynamic Macroeconomic Theory, Harvard University Press, December 1984 .

Storesletten, Kjetil, Chris Telmer, and Amir Yaron, "Cyclical Dynamics of Idiosyncratic Labor Market Risk," The Journal of Political Economy, 2004.

Uhlig, Harald, "A Law of Large Numbers for Large Economies," Economic Theory, 1996, $8,41-50$.

Whitelaw, Robert F., "Time-Varying Sharpe Ratios and Market Timing," 1997. Unpublished paper, NYU Stern School of Business. 
Yogo, Motohiro, "A Consumption-Based Explanation of the Cross-Section of Expected Stock Returns," Journal of Finance, Forthcoming 2005. 
Figure 1: Summary Conditional Asset Pricing Moments.

The figure plots the expected excess return on a claim to aggregate consumption (panel 1), its conditional standard deviation (panel 2) and its Sharpe ratio (panel 3). All series are averaged over histories and plotted against the housing collateral ratio, the ratio of housing wealth to total wealth (housing plus human wealth). The model simulation, discussed in section 2.1 , uses the benchmark calibration, discussed in section 2.2 .
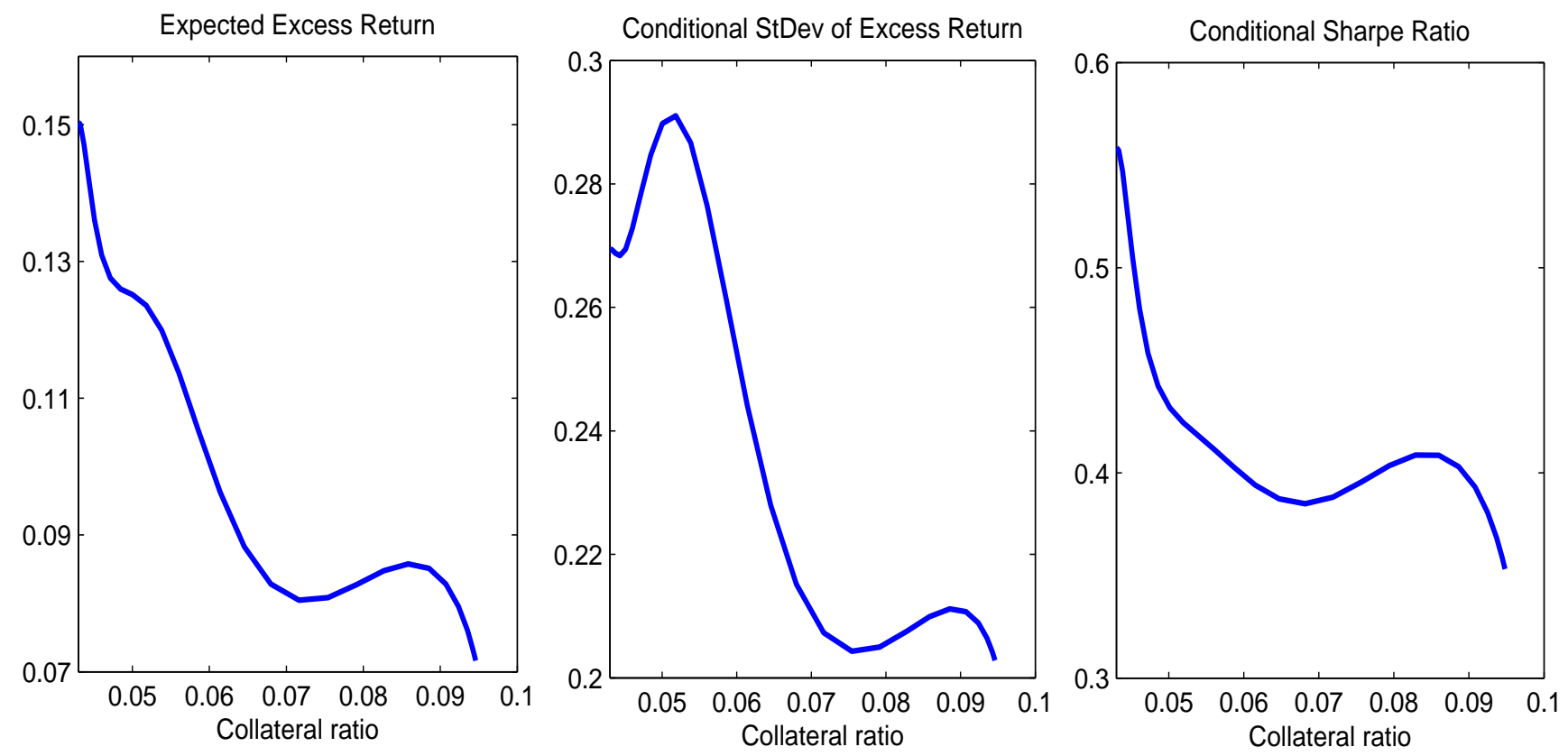
Figure 2: Return Spreads in Book-to-Market Portfolios

This graph plots returns of the 9 highest book-to-market decile portfolios in excess of the return on the first decile portfolio. It plots the model-implied return spreads on the horizontal axis against the return spreads observed in the data (vertical axis). The stock returns on the book-to-market decile portfolios are from Kenneth French's web site. the data are annual for the period 1945-2003. The first panel shows model-generated spreads computed using a mortgage-based collateral measure. The second panel uses a residential wealth-based collateral measure. The model simulation uses the benchmark calibration, discussed in section 2.2 , and the computation is detailed in section 4.2 .
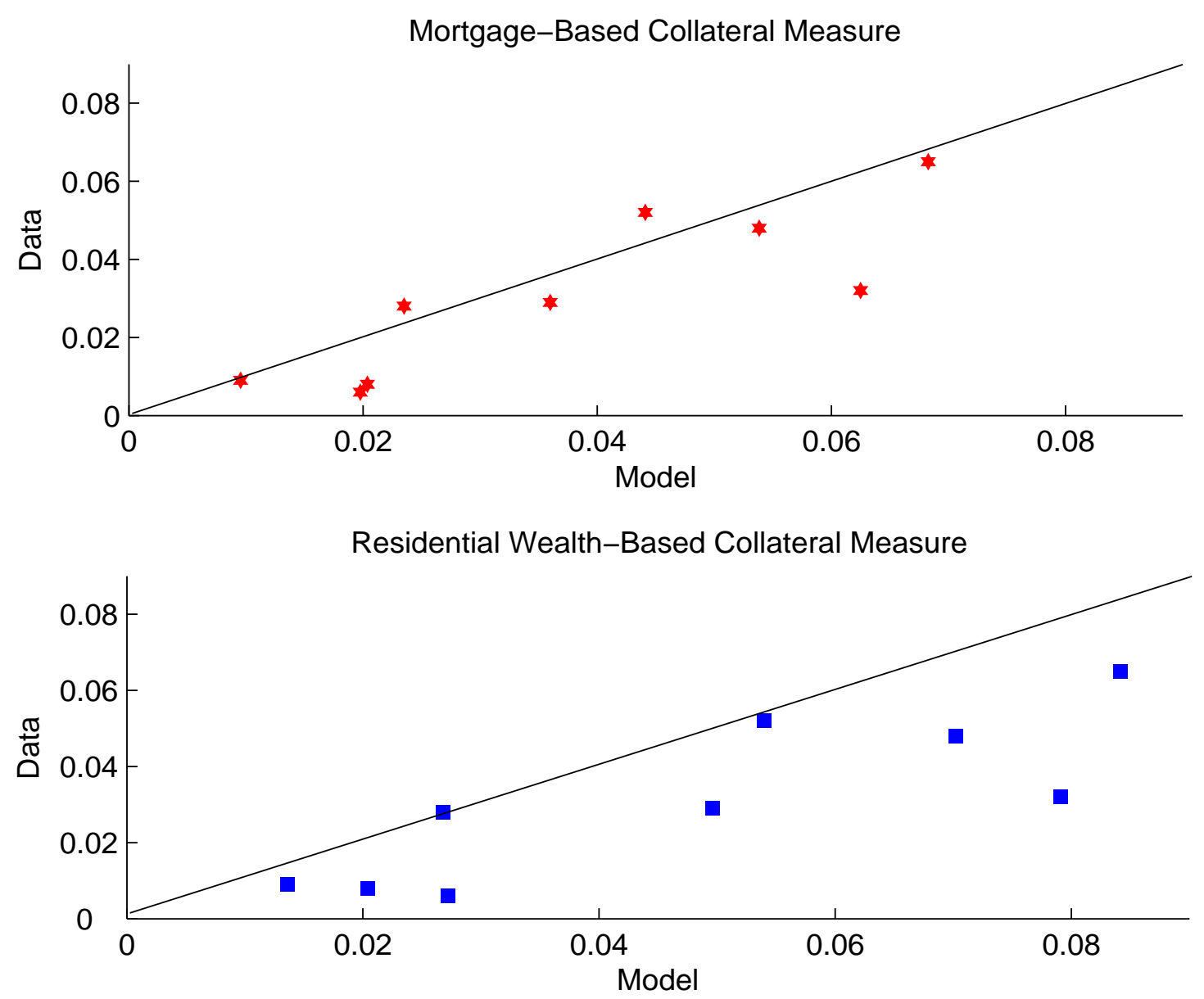
Figure 3: Time-Variation in Risk-free rate: Data and Model.

The two plots in the first row of the figure plot the 9-year moving average of the annual T-bill rate and the collateral ratio in the data (dashed line). In the left panel the housing collateral ratio is measured as the percentage deviation of the mortgage-based collateral measure from its long-run trend $(M O / Y)$. The right panel uses the residential wealth-based collateral measure $(R W / Y)$. The annual risk-free rate is computed from monthly deflated T-Bill returns: $r_{t, t+1}^{f}=12 \times\left(\left(1+i_{t, t+1}\right)^{(1 / 12)}-\left(1+\pi_{t, t+1}\right)\right)$, where $i$ is the annual nominal holding period return on 3-month T-bills from CRSP and $\pi$ is the monthly inflation computed from the BLS consumer price index. The panels in the second row plot the same statistics for the benchmark model. I.e., we feed in the observed aggregate consumption growth and housing collateral data and compute the model-implied 9-year moving average of the annual risk-free rate.
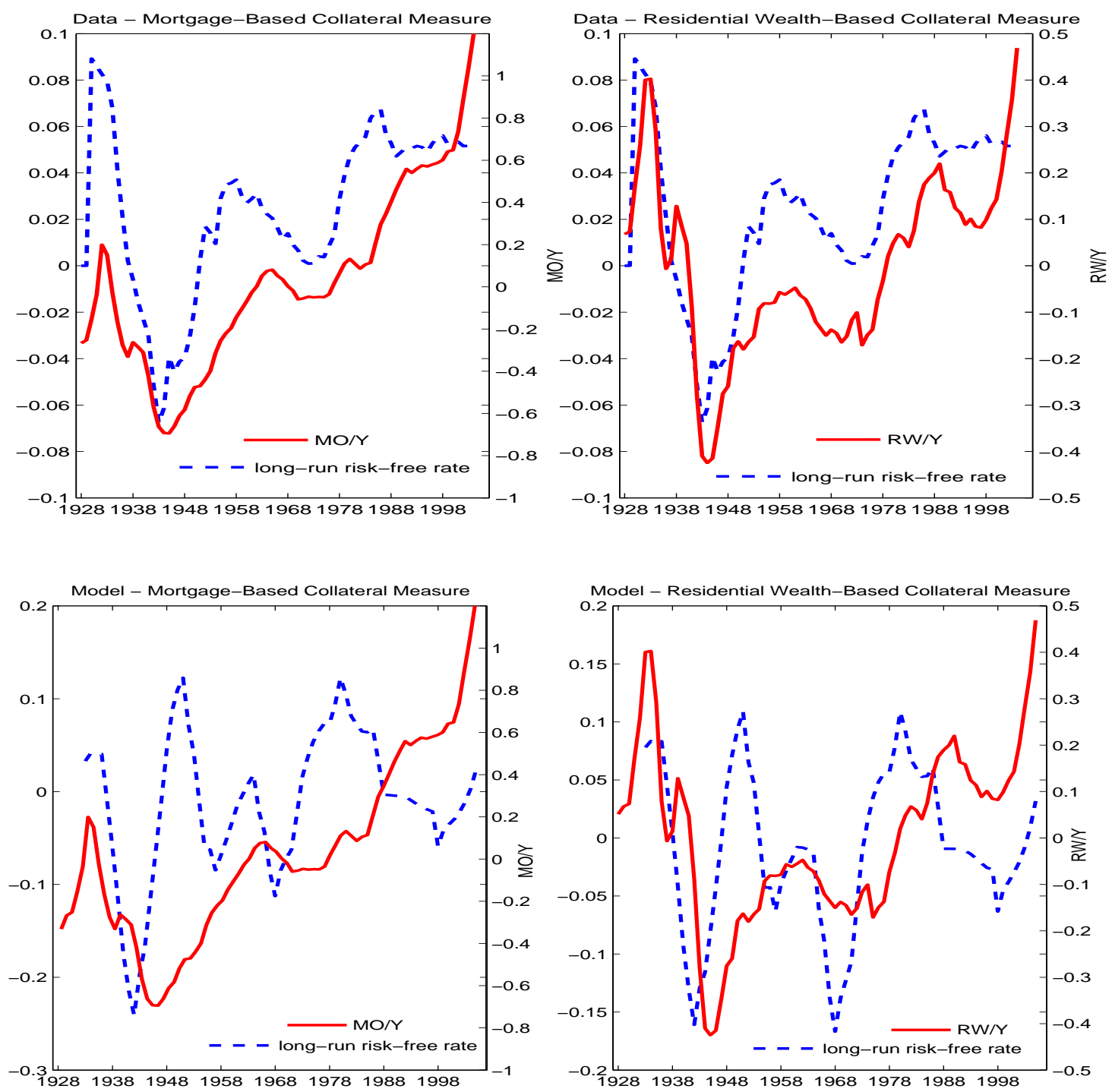
Figure 4: Time-Variation in Equity Premium: Model and US Data

This panel plots the conditional expected excess stock market return, its conditional standard deviation and the conditional Sharpe ratio in the model (left column) and in the data (right column). The modelsimulated data were generated by feeding in observed aggregate consumption growth $\left\{z_{t}\right\}_{t=1929}^{T=2000}$ and the observed collateral ratio, measured based on mortgages $\left\{\frac{M O_{t}}{Y_{t}}\right\}_{t=1929}^{T=2000}$ into the benchmark model. The top panel plots the expected excess return on a claim to aggregate consumption. The middle panel plots the conditional standard deviation of the excess return on a claim to aggregate consumption. The bottom panel plots the conditional Sharpe ratio, the ratio of the expected excess return over its standard deviation. In the right column all conditional asset pricing moments are constructed from the data in the following way. The expected excess return, plotted in the top right panel, is computed by projecting the annual CRSP value-weighted stock return in excess of the annual return on the Fama 3-month T-bill return on the mortgage-based housing collateral ratio and the Fama 3-month T-bill return (less inflation over the previous year). The middle panel plots the conditional standard deviation of the excess return. It is computed from daily data as $\sum_{k \in \text { year }}\left(R_{k}^{C R S P}-(1+i)^{1 / 360}\right)^{2}$. We use daily S\&P500 data from Global Financial Data before 1960, and daily CRSP data afterwards. The expected standard deviation is computed by projecting this standard deviation on two lags, the mortgage-based housing collateral ratio and the Fama 3-month T-bill return (less inflation over the previous year). The bottom right panel plots the conditional Sharpe ratio, the ratio of the expected excess return over its standard deviation.
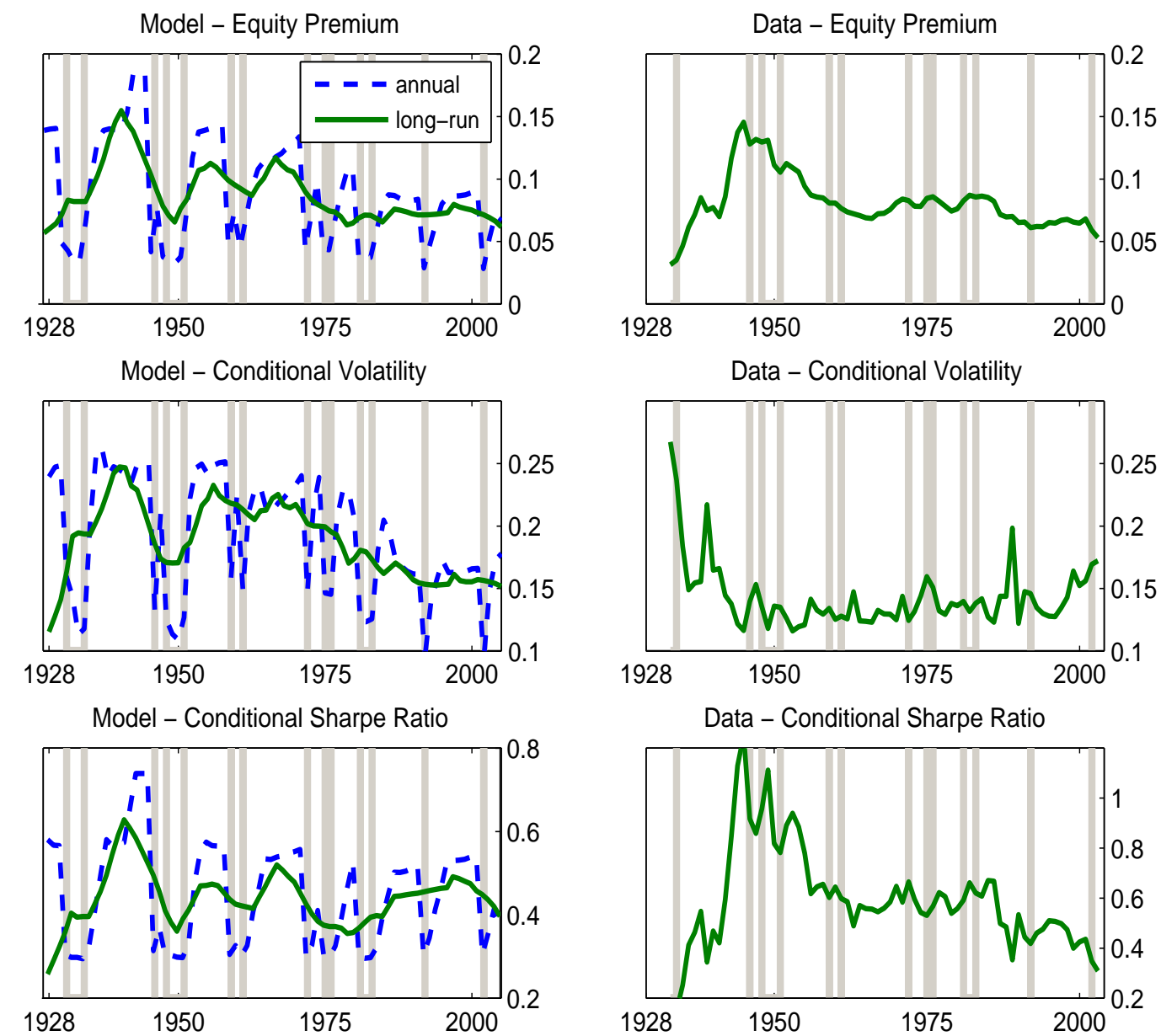
Figure 5: Beta Estimates for Book-to-Market Decile Returns in Data.

This figure plots consumption betas when collateral is abundant (left panels) and when collateral is scarce (right panels) for ten book-to-market decile portfolios. The portfolios are organized from the lowest book-to-market decile (growth) on the left to the highest book-to-market decile (value) on the right of each horizontal axis. The betas are estimated from OLS regression of excess returns of the 10 book-to-market deciles on a constant, the collateral scarcity measure $\widetilde{m y} y_{t}$, the aggregate consumption growth rate $\Delta \log c_{t+1}^{a}$, the interaction term $\widetilde{m y}_{t} \Delta \log c_{t+1}^{a}$, the aggregate expenditure ratio growth rate $\Delta \log r_{t+1}$, and the interaction term $\widetilde{m y} t_{t} \Delta \log r_{t+1}$. These are the five risk factors in the collateral model. In the first panel the housing collateral ratio is based on the value of outstanding mortgages; in the second panel the housing collateral ratio is based on the value of residential real estate wealth. The data are annual for the period 1930-2003.
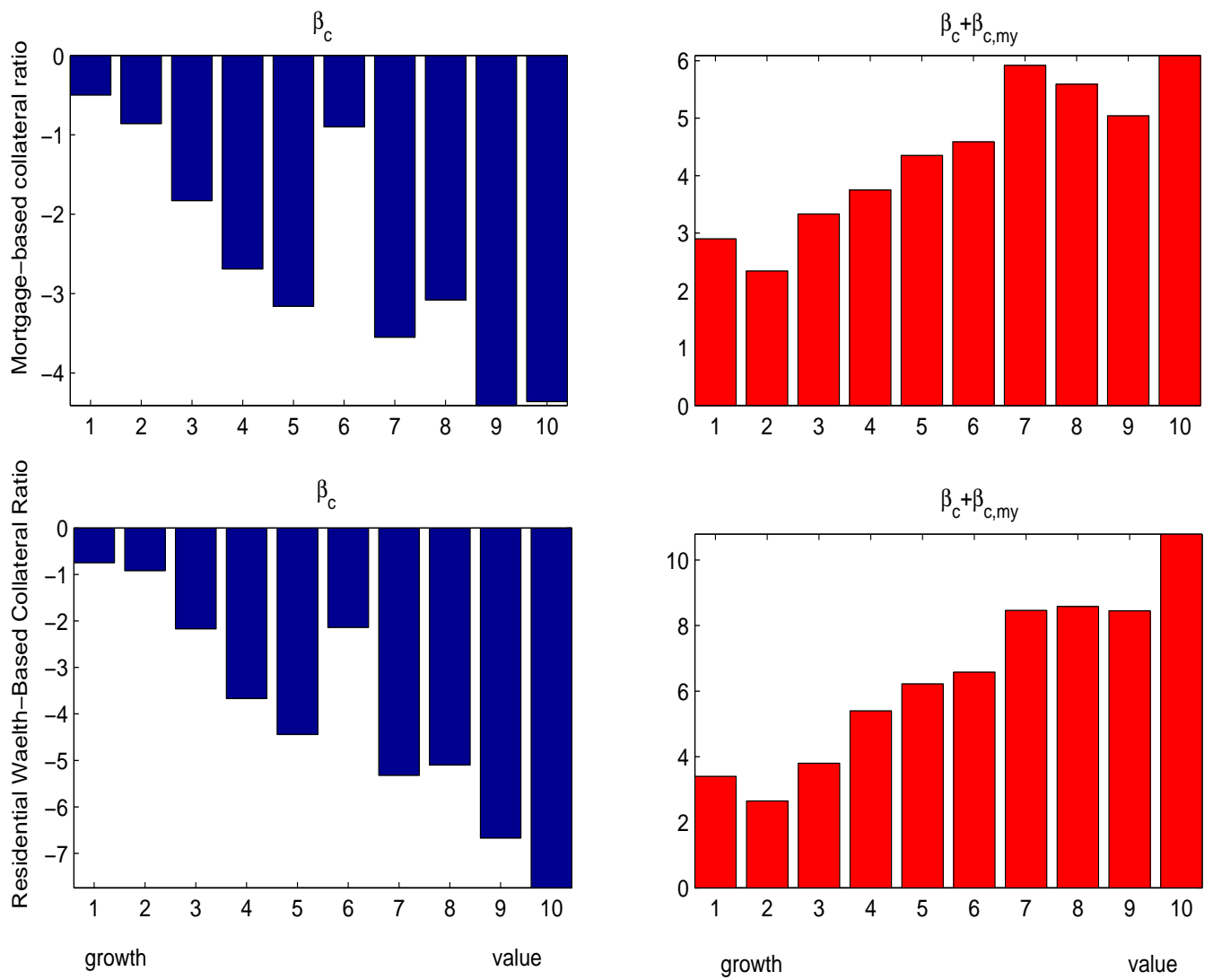
Figure 6: Term Structure of Consumption Strips.

The first panel plots the conditional expected excess return on a levered claim to aggregate consumption $k$ periods from now, where $k=2,3, \ldots, 45$. The second panel shows the corresponding Sharpe ratios. Panel 3 plots the risk premium for the duration-based portfolios against duration. Panel 4 plots the Sharpe ratio for the duration-based portfolios against duration. The leverage parameter $\kappa$ is 2 .
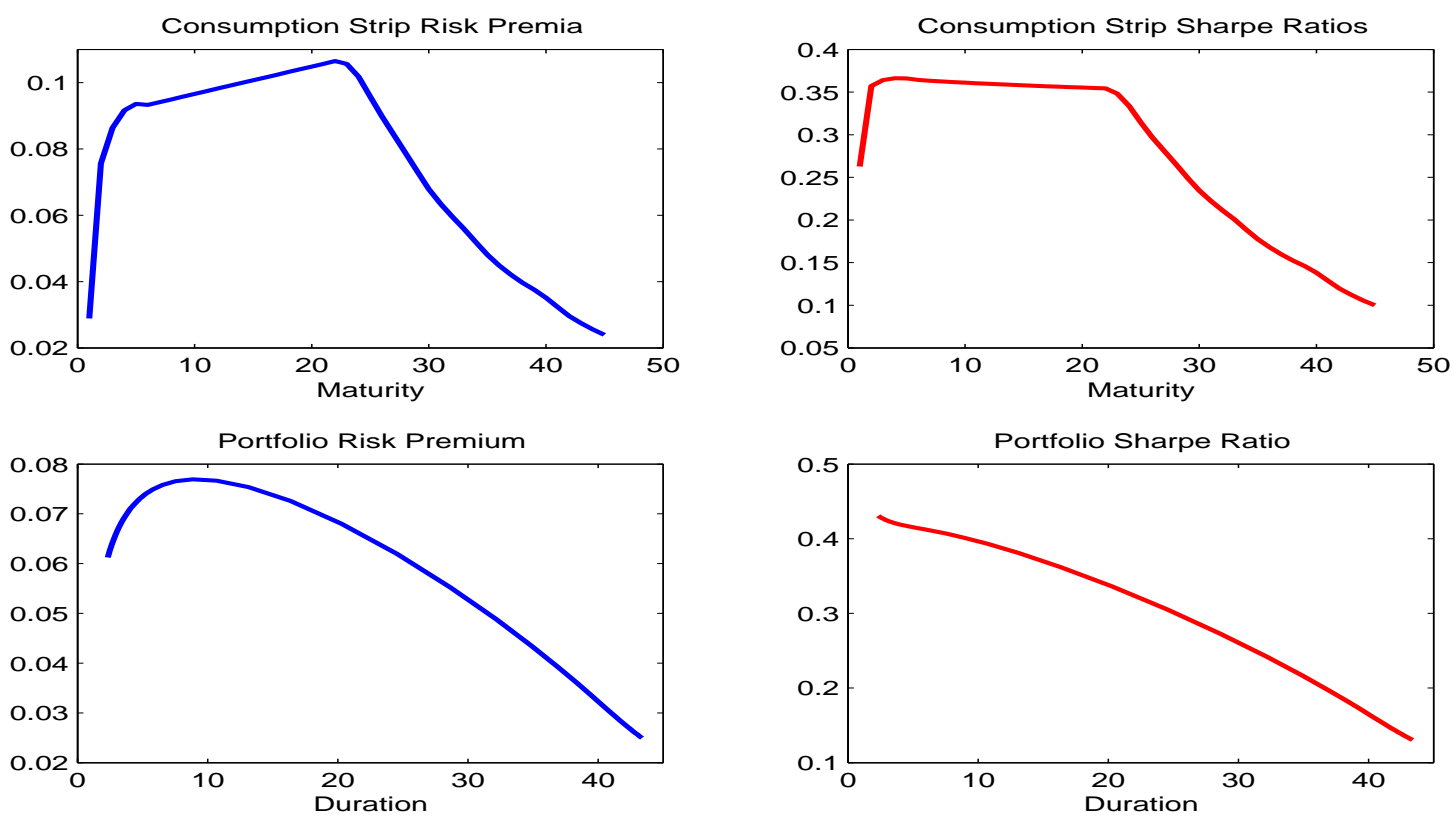
Figure 7: Risk Sharing, Conditional Asset Pricing Moments and Collateral Ratio

The graphs display a two hundred period model simulation under the benchmark parametrization (see Table 1). The shocks are the same in each panel. The first panel plots the non-housing expenditure ratio $r$. The second panel plots the cross-sectional standard deviation of consumption growth across households $\left(\sigma_{t}\left[\Delta \log c_{t+1}\right]\right)$. The third panel is the aggregate weight shock $g_{t+1}$. The fourth panel plots the equity premium predicted by the model, i.e. the expected excess return on a non-levered claim to aggregate consumption $E_{t}\left[R_{t+1}^{c, e}\right]$. The fifth panel is the conditional standard deviation of this excess return $\sigma_{t}\left[R_{t+1}^{c, e}\right]$. The sixth panel is the conditional Sharpe ratio $E_{t}\left[R_{t+1}^{c, e}\right] / \sigma_{t}\left[R_{t+1}^{c, e}\right]$. Each of these series are measured against the left axis and plotted in a single blue line. The housing collateral ratio my is measured against the right axis and plotted in a bold red line.
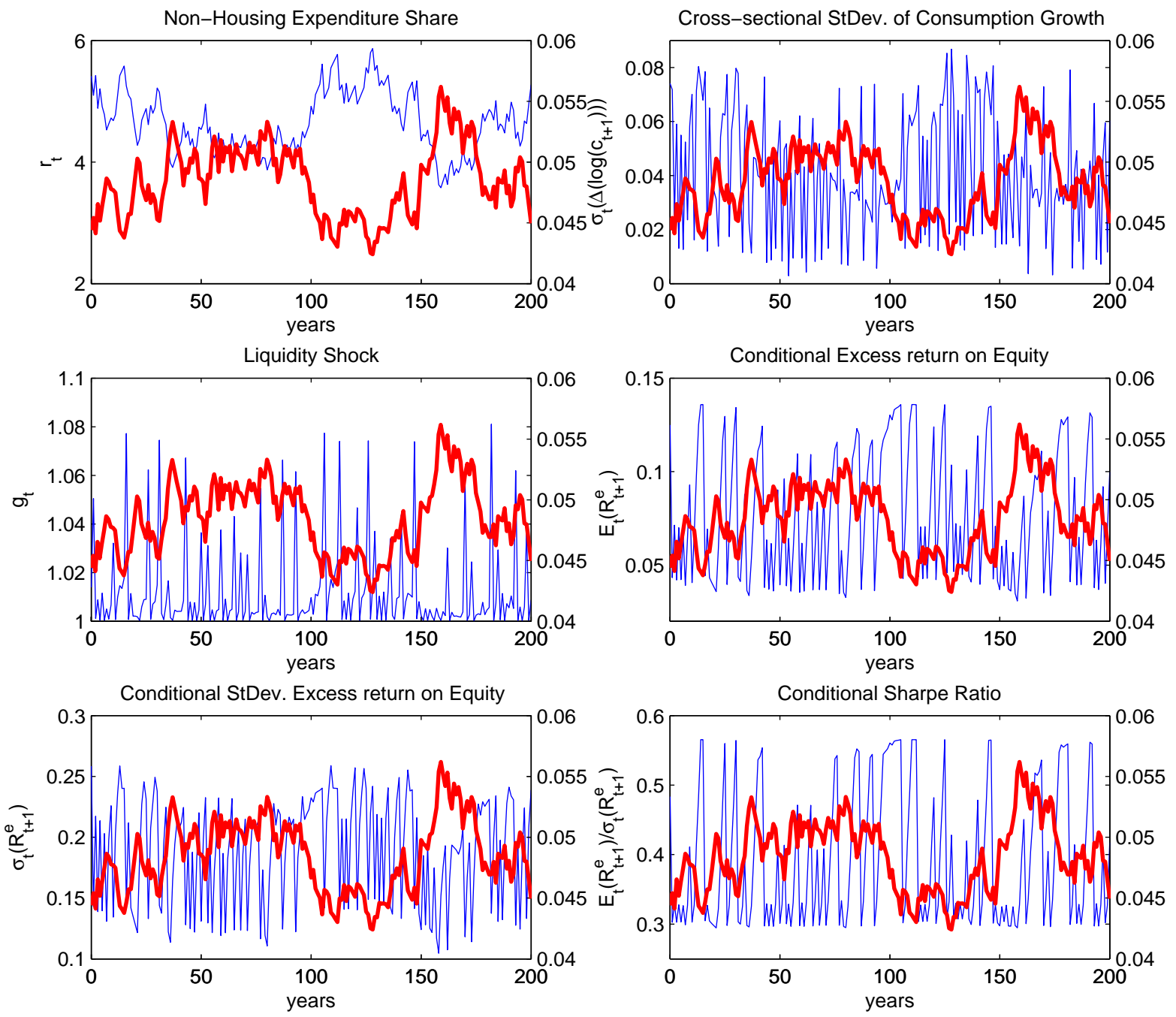
Figure 8: Summary Conditional Asset Pricing Moments.

This graph reports average asset pricing moments from a long model simulation under the benchmark parametrization. All series are averaged over histories $\left(z_{t-1}, \cdots, z_{t-k}\right)$, sorted into low $z_{t}\left(\lambda\left(z_{t}\right)=0.96\right.$, full line) and high $z_{t}$ observations $\left(\lambda\left(z_{t}\right)=1.04\right.$, dashed line) and plotted against the housing collateral ratio (horizontal axes). The first row of the figure plots the expected excess return on a claim to aggregate consumption (panel 1), its conditional standard deviation (panel 2) and its Sharpe ratio (panel 3). The second row plots the conditional market price of risk (panel 4), the conditional price-dividend ratio (panel 5), and the risk-free rate (panel 6).
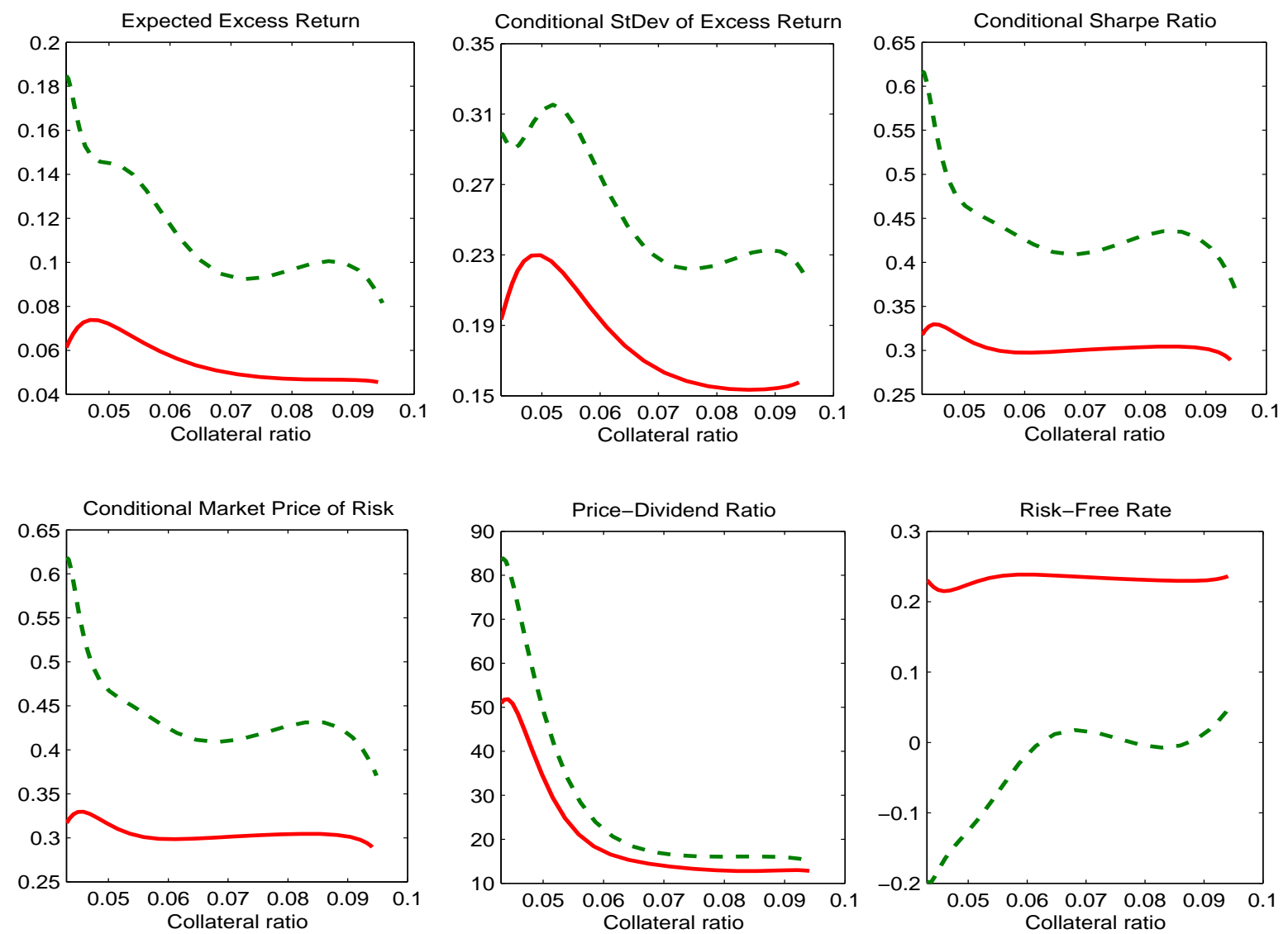
Table 1: Parameter Calibration

\begin{tabular}{lcc}
\hline \hline & & \\
Parameter & Benchmark & Sensitivity Analysis \\
\hline$\gamma$ & 8 & {$[2,5,10]$} \\
$\varepsilon$ & .05 & {$[.15, .75]$} \\
$\psi$ & 1 & $\cdot$ \\
$\bar{r}$ & 4.26 & $\cdot$ \\
$\rho_{r}$ & .96 &. \\
$b_{r}$ & .93 & 0 \\
$\sigma_{r}$ & .03 &. \\
$E[m y]$ & .05 & .10 \\
$\lambda$ & {$[1.04, .96]$} &. \\
$\eta$ & $1.6578, .7952, .3422, .2048]$ & 3 \\
$\kappa$ & 1 & \\
\hline \hline
\end{tabular}


Table 2: Decade-by-Decade Volatility of Asset Returns.

Panel 1 reports the volatility of excess stock returns and the risk-free rate in the data. $R^{e}$ is the excess return on the CRSP valueweighted stock index. The nominal risk-free rate $i_{t, t+1}$ is the annual return on the CRSP 3 -month T-bill rate. Inflation $\pi_{t, t+1}$ is computed from the BLS consumer price index series. Column 1 reports the annualized standard deviation of excess stock returns, computed as the sample standard deviation of monthly excess returns, where $R_{t+1}^{e}=12 \times\left(\left(1+R_{t, t+1}\right)-\left(1+i_{t, t+1}\right)^{1 / 12}\right)$. The second column reports the annualized standard deviation of the ex-post risk-free rate $r_{t, \text { ex }}^{f}$ post $=12 \times\left(\left(1+i_{t, t+1}\right)^{(1 / 12)}-(1+\right.$ $\left.\pi_{t, t+1}\right)$ ). To minimize the effect of inflation surprises, column 3 reports the annualized standard deviation of an ex-ante risk-free rate which subtracts out the previous month's inflation rate instead: $r_{t, e x-a n t e}^{f}=12 \times\left(\left(1+i_{t, t+1}\right)^{(1 / 12)}-\left(1+\pi_{t-1, t}\right)\right)$. To compute decade-averages, we only use the last month in each year. Panel 2 reports the same statistics for the model under the benchmark parametrization. The model-simulated data were generated by feeding in observed aggregate consumption growth $\left\{z_{t}\right\}_{t=1929}^{T=2000}$ and the observed collateral ratio, measured either based on mortgages $\left\{\frac{M O_{t}}{Y_{t}}\right\}_{t=1929}^{T=2000}$ or on residential wealth $\left\{\frac{R W_{t}}{Y_{t}}\right\}_{t=1929}^{T=2000}$. If aggregate consumption growth at $t$ is one standard deviation below the mean, $z_{t}$ is the low consumption growth state, else $z_{t}$ is classified as the high consumption growth state. This procedure matches the unconditional probability of a low aggregate consumption growth in the model to that in the data. In the model, $R^{e}$ is the excess return on an un-levered claim to aggregate consumption. Panel 3 reports the same statistics as panel 2, but for a model with Epstein and Zin (1991) preferences. The intertemporal elasticity of substitution is set to 0.2 and the coefficient of relative risk aversion is held at its benchmark value of 8 .

\begin{tabular}{|c|c|c|c|c|c|}
\hline & \multicolumn{5}{|c|}{ Panel 1: Data } \\
\hline & \multicolumn{2}{|l|}{$\sigma\left(R_{t}^{e}\right)$} & $\sigma\left(r_{t, \text { ex-post }}^{f}\right)$ & $\sigma\left(r_{t, \text { ex-ante }}^{f}\right)$ & \\
\hline 1931-1940 & \multicolumn{2}{|l|}{0.31} & 0.06 & \multicolumn{2}{|l|}{0.07} \\
\hline 1941-1950 & \multicolumn{2}{|l|}{0.13} & 0.08 & \multicolumn{2}{|l|}{0.10} \\
\hline $1951-1960$ & \multicolumn{2}{|l|}{0.10} & 0.03 & \multicolumn{2}{|l|}{0.04} \\
\hline $1961-1970$ & \multicolumn{2}{|l|}{0.12} & 0.02 & \multicolumn{2}{|l|}{0.02} \\
\hline 1971-1980 & \multicolumn{2}{|l|}{0.15} & 0.02 & \multicolumn{2}{|l|}{0.03} \\
\hline 1981-1990 & \multicolumn{2}{|l|}{0.15} & 0.03 & \multicolumn{2}{|l|}{0.02} \\
\hline \multirow[t]{4}{*}{ 1991-2000 } & \multicolumn{2}{|l|}{0.11} & 0.01 & \multicolumn{2}{|l|}{0.02} \\
\hline & \multicolumn{5}{|c|}{ Panel 2: Benchmark Model } \\
\hline & \multicolumn{2}{|c|}{$M O / Y$} & & \multicolumn{2}{|c|}{$R W / Y$} \\
\hline & $\sigma\left(R_{t}^{e}\right)$ & $\sigma\left(r_{t}^{f}\right)$ & & $\sigma\left(R_{t}^{e}\right)$ & $\sigma\left(r_{t}^{f}\right)$ \\
\hline $1931-1940$ & 0.36 & 0.21 & & 0.23 & 0.16 \\
\hline 1941-1950 & 0.33 & 0.26 & & 0.43 & 0.22 \\
\hline $1951-1960$ & 0.18 & 0.19 & & 0.17 & 0.17 \\
\hline $1961-1970$ & 0.10 & 0.12 & & 0.08 & 0.15 \\
\hline $1971-1980$ & 0.16 & 0.15 & & 0.16 & 0.16 \\
\hline 1981-1990 & 0.14 & 0.14 & & 0.16 & 0.14 \\
\hline \multirow[t]{4}{*}{ 1991-2000 } & 0.12 & 0.11 & & 0.12 & 0.11 \\
\hline & \multicolumn{5}{|c|}{ Panel 3: Model with Epstein-Zin Preferences } \\
\hline & \multicolumn{2}{|c|}{$M O / Y$} & & \multicolumn{2}{|c|}{$R W / Y$} \\
\hline & $\sigma\left(R_{t}^{e}\right)$ & $\sigma\left(r_{t}^{f}\right)$ & & $\sigma\left(R_{t}^{e}\right)$ & $\sigma\left(r_{t}^{f}\right)$ \\
\hline 1931-1940 & 0.29 & 0.10 & & 0.25 & 0.07 \\
\hline 1941-1950 & 0.17 & 0.10 & & 0.27 & 0.08 \\
\hline $1951-1960$ & 0.09 & 0.08 & & 0.09 & 0.07 \\
\hline $1961-1970$ & 0.07 & 0.04 & & 0.04 & 0.05 \\
\hline 1971-1980 & 0.08 & 0.06 & & 0.08 & 0.06 \\
\hline 1981-1990 & 0.05 & 0.05 & & 0.09 & 0.05 \\
\hline 1991-2000 & 0.04 & 0.03 & & 0.06 & 0.04 \\
\hline
\end{tabular}


Table 3: Decade-by-Decade Equity Premium.

This table reports the benchmark model's predictions for the equity premium and the realized excess returns on stocks. $R_{t+1}^{e}=$ $R_{t+1}^{c, e}$ is the excess return on an un-levered claim to aggregate consumption. We report the sample average of the conditional expected excess return $\widehat{E}\left(E_{t}\left[R_{t+1}^{e}\right]\right)$ and the sample average of the realized excess return $\widehat{E}\left(R_{t+1}^{e}\right)$ for each decade. The modelsimulated data were generated by feeding in observed aggregate consumption growth $\left\{z_{t}\right\}_{t=1929}^{T=2000}$ and the observed collateral ratio, measured either based on mortgages $\left\{\frac{M O_{t}}{Y_{t}}\right\}_{t=1929}^{T=2000}$ (column 2 and 3) or on residential wealth $\left\{\frac{R W_{t}}{Y_{t}}\right\}_{t=1929}^{T=2000}$ (column 4 and 5).

\begin{tabular}{ccccc}
\hline \hline & & $M O / Y$ & \multicolumn{2}{c}{$R W / Y$} \\
\hline $1931-1940$ & $\widehat{E}\left(E_{t}\left[R_{t+1}^{e}\right]\right)$ & $\widehat{E}\left(R_{t+1}^{e}\right)$ & $\widehat{E}\left(E_{t}\left[R_{t+1}^{e}\right]\right)$ & $\widehat{E}\left(R_{t+1}^{e}\right)$ \\
$1941-1950$ & 0.097 & 0.175 & 0.080 & 0.093 \\
$1951-1960$ & 0.097 & 0.055 & 0.092 & 0.093 \\
$1961-1970$ & 0.106 & 0.086 & 0.101 & 0.112 \\
$1971-1980$ & 0.112 & 0.204 & 0.128 & 0.265 \\
$1981-1990$ & 0.071 & -0.015 & 0.077 & -0.019 \\
$1991-2000$ & 0.072 & 0.072 & 0.080 & 0.079 \\
$2001-2004$ & 0.075 & 0.154 & 0.094 & 0.147 \\
\hline \hline
\end{tabular}


Table 4: Predictability of K-Year Excess Returns: Data and Model.

Results of regressing $\log K$-horizon excess returns on the housing collateral ratio. The intercept is $b_{0}$, the slope coefficient is $b_{1}$. The first panel reports the results in the data. The t-stats in brackets are computed using the Newey West covariance matrix with $K$ lags. The returns are cum-dividend returns on the value-weighted CRSP index. The collateral scarcity measure $\widetilde{m y}{ }_{t}$ is based on the market value of outstanding mortgages. The long sample contains annual data from 1930-2003. The post-war sample is from 1945-2003. The second panel reports the same regressions inside the model. The regressions were obtained by simulating the model for 10,000 periods under the benchmark parametrization with leverage parameter $\kappa=1$ (left columns) and $\kappa=3$ (right columns).

\begin{tabular}{|c|c|c|c|c|c|c|}
\hline & $b_{0}$ & $b_{1}$ & $R^{2}$ & $b_{0}$ & $b_{1}$ & $R^{2}$ \\
\hline \multirow[b]{2}{*}{ Horizon } & \multicolumn{6}{|c|}{ Panel 1: Data } \\
\hline & \multicolumn{3}{|c|}{ Entire Sample } & \multicolumn{3}{|c|}{ Post-War Sample } \\
\hline 1 & $\begin{array}{c}0.01 \\
{[0.24]}\end{array}$ & $\begin{array}{c}0.15 \\
{[1.25]}\end{array}$ & 0.02 & $\begin{array}{c}0.02 \\
{[0.63]}\end{array}$ & $\begin{array}{c}0.15 \\
{[1.73]}\end{array}$ & 0.04 \\
\hline 2 & $\begin{array}{c}0.07 \\
{[0.66]}\end{array}$ & $\begin{array}{c}0.25 \\
{[1.11]}\end{array}$ & 0.03 & $\begin{array}{c}0.06 \\
{[0.83]}\end{array}$ & $\begin{array}{c}0.31 \\
{[1.75]}\end{array}$ & 0.07 \\
\hline 3 & $\begin{array}{c}0.16 \\
{[1.02]}\end{array}$ & $\begin{array}{c}0.31 \\
{[0.97]}\end{array}$ & 0.03 & $\begin{array}{c}0.12 \\
{[1.04]}\end{array}$ & $\begin{array}{c}0.46 \\
{[1.80]}\end{array}$ & 0.09 \\
\hline 4 & $\begin{array}{c}0.29 \\
{[1.50]}\end{array}$ & $\begin{array}{c}0.32 \\
{[0.80]}\end{array}$ & 0.02 & $\begin{array}{c}0.22 \\
{[1.42]}\end{array}$ & $\begin{array}{c}0.56 \\
{[1.82]}\end{array}$ & 0.09 \\
\hline 5 & $\begin{array}{c}0.38 \\
{[1.83]}\end{array}$ & $\begin{array}{c}0.47 \\
{[1.16]}\end{array}$ & 0.03 & $\begin{array}{c}0.34 \\
{[1.67]}\end{array}$ & $\begin{array}{c}0.66 \\
{[1.77]}\end{array}$ & 0.08 \\
\hline 6 & $\begin{array}{c}0.41 \\
{[1.70]}\end{array}$ & $\begin{array}{c}0.79 \\
{[1.73]}\end{array}$ & 0.07 & $\begin{array}{c}0.43 \\
{[1.58]}\end{array}$ & $\begin{array}{c}0.89 \\
{[1.86]}\end{array}$ & 0.10 \\
\hline 7 & $\begin{array}{c}0.41 \\
{[1.32]}\end{array}$ & $\begin{array}{c}1.20 \\
{[2.11]}\end{array}$ & 0.12 & $\begin{array}{c}0.49 \\
{[1.30]}\end{array}$ & $\begin{array}{c}1.26 \\
{[2.02]}\end{array}$ & 0.14 \\
\hline 8 & $\begin{array}{c}0.37 \\
{[0.91]}\end{array}$ & $\begin{array}{c}1.80 \\
{[2.71]}\end{array}$ & 0.18 & $\begin{array}{c}0.50 \\
{[1.01]}\end{array}$ & $\begin{array}{c}1.79 \\
{[2.26]}\end{array}$ & 0.19 \\
\hline
\end{tabular}

\section{Panel 2: Model}

\begin{tabular}{lcccccc} 
Horizon & \multicolumn{3}{c}{ Leverage $=\mathbf{1}$} & \multicolumn{3}{c}{ Leverage=3 } \\
\hline 1 & -0.00 & 0.13 & 0.01 & 0.03 & 0.12 & 0.00 \\
2 & -0.07 & 0.32 & 0.02 & 0.01 & 0.29 & 0.01 \\
3 & -0.16 & 0.54 & 0.03 & -0.04 & 0.47 & 0.01 \\
4 & -0.29 & 0.81 & 0.04 & -0.12 & 0.70 & 0.02 \\
5 & -0.45 & 1.11 & 0.06 & -0.23 & 0.96 & 0.03 \\
6 & -0.62 & 1.42 & 0.07 & -0.36 & 1.24 & 0.04 \\
7 & -0.81 & 1.77 & 0.09 & -0.50 & 1.54 & 0.05 \\
8 & -1.01 & 2.12 & 0.11 & -0.65 & 1.86 & 0.05 \\
\hline \hline
\end{tabular}


Table 5: Long-Term Sharpe Ratios in Data.

the table reports coefficient estimates for $R_{t+1}^{e}=b_{0}+b_{1} R_{t}+b_{2} d p_{t}+b_{3} l c_{t}+b_{4} \widetilde{m y_{t}}+\varepsilon_{t+1}$ and $V o l_{t+1}=a_{0}+a_{1} d p_{t}+a_{2} l c_{t}+a_{3} \widetilde{m y}_{t}+$ $a_{4} \mathrm{Vol}_{t}+a_{5} \mathrm{Vol}_{t-1}$. The variables $d p, l c$ and $\widetilde{m y}$ are the dividend yield, the labor income-consumption ratio, and the housing collateral scarcity measure based on the value of mortgages. In particular $\widetilde{m y_{t}}=\max \left(m y_{t}\right)-m y_{t} /\left(\max \left(m y_{t}\right)-\min \left(m y_{t}\right)\right)$, where $\max \left(m y_{t}\right)$ and $\min \left(m y_{t}\right)$ are the sample minimum and maximum of the housing collateral ratio $m y$. $R^{e}$ denotes the value weighted market return in excess of a 1 month T-bill return. Vol $t$ is the standard deviation of the 12 monthly returns in year $t$. $R 1, R 5, R 10$ denote the 1-year, 5-year and 10-year ahead cumulative excess returns. The estimation is by GMM with the OLS normal conditions as moment conditions. Standard errors are Newey-West with lag length 3 . The estimation period is 1927-1992, the longest common sample. The predicted Sharpe ratio is formed as the ratio of the predicted mean excess return to the predicted standard deviation. The last three rows indicate the sample mean of the predicted Sharpe ratio, its sample standard deviation, and the sample correlation between the Sharpe ratio and the housing collateral scarcity measure $\widetilde{m y}$.

\begin{tabular}{|c|c|c|c|c|c|c|}
\hline Regressors & $\mathrm{R} 1$ & Vol1 & $\mathrm{R} 5$ & Vol5 & $\mathrm{R} 10$ & Vol10 \\
\hline $\begin{array}{l}\text { constant } \\
\text { (s.e.) }\end{array}$ & $\begin{array}{l}-.24 \\
(.34)\end{array}$ & $\begin{array}{l}.09 \\
(.05)\end{array}$ & $\begin{array}{c}.71 \\
(0.28)\end{array}$ & $\begin{array}{l}-.004 \\
(.04)\end{array}$ & $\begin{array}{l}.76 \\
(.42)\end{array}$ & $\begin{array}{l}.05 \\
(.04)\end{array}$ \\
\hline $\begin{array}{l}\text { lag ret } \\
\text { (s.e.) }\end{array}$ & $\begin{array}{l}.04 \\
(.13)\end{array}$ & & $\begin{array}{l}.74 \\
(.13)\end{array}$ & & $\begin{array}{l}.76 \\
(.08)\end{array}$ & \\
\hline $\begin{array}{l}\text { dp } \\
\text { (s.e.) }\end{array}$ & $\begin{array}{c}1.07 \\
(2.00)\end{array}$ & $\begin{array}{l}.33 \\
(.27)\end{array}$ & $\begin{array}{l}-1.20 \\
(3.16)\end{array}$ & $\begin{array}{l}.40 \\
(.22)\end{array}$ & $\begin{array}{c}.26 \\
(3.00)\end{array}$ & $\begin{array}{l}.12 \\
(.21)\end{array}$ \\
\hline $\begin{array}{l}\text { lc } \\
\text { (s.e.) }\end{array}$ & $\begin{array}{l}.22 \\
(.32)\end{array}$ & $\begin{array}{l}-.07 \\
(.05)\end{array}$ & $\begin{array}{l}-.76 \\
(.33)\end{array}$ & $\begin{array}{l}.03 \\
(.03)\end{array}$ & $\begin{array}{l}-.92 \\
(.45)\end{array}$ & $\begin{array}{l}-.03 \\
(.04)\end{array}$ \\
\hline $\begin{array}{l}\widetilde{m y} \\
\text { (s.e.) }\end{array}$ & $\begin{array}{c}.02 \\
(0.20)\end{array}$ & $\begin{array}{l}-.01 \\
(.02)\end{array}$ & $\begin{array}{l}.48 \\
(.20)\end{array}$ & $\begin{array}{l}-.04 \\
(.02)\end{array}$ & $\begin{array}{l}.70 \\
(.23)\end{array}$ & $\begin{array}{c}.01 \\
(.02)\end{array}$ \\
\hline $\begin{array}{l}\text { lag vol } \\
\text { (s.e.) }\end{array}$ & & $\begin{array}{l}.51 \\
(.20)\end{array}$ & & $\begin{array}{l}.96 \\
(.12)\end{array}$ & & $\begin{array}{l}.80 \\
(.12)\end{array}$ \\
\hline $\begin{array}{l}2 \text { lag vol } \\
\text { (s.e.) }\end{array}$ & & $\begin{array}{l}-.18 \\
(.17)\end{array}$ & & $\begin{array}{l}-.19 \\
(.11)\end{array}$ & & $\begin{array}{c}.03 \\
(.10)\end{array}$ \\
\hline E[Sharpe] & \multicolumn{2}{|c|}{.40} & \multicolumn{2}{|c|}{1.02} & \multicolumn{2}{|l|}{1.12} \\
\hline$\sigma[$ Sharpe $]$ & \multicolumn{2}{|c|}{.10} & \multicolumn{2}{|c|}{.18} & \multicolumn{2}{|l|}{.20} \\
\hline$\rho[$ Sharpe, $\widetilde{m y}]$ & \multicolumn{2}{|c|}{.26} & \multicolumn{2}{|c|}{.32} & \multicolumn{2}{|l|}{.50} \\
\hline
\end{tabular}


Table 6: Value Premium in Data and in the Collateral Model

Panel 1 reports moments of book-to-market decile portfolio returns in excess of a risk-free rate: the sample mean, the sample volatility and the Sharpe ratio. The risk-free rate is the annual return on a 3-month T-Bill. The value-weighted stock returns on the book-to-market deciles are annual for 1930-2003 and 1945-2003, and the source is Kenneth French's web site. Panel 2 reports the decile returns generated by the model as described in section 5.1. The panel reports expected returns, standard deviation and Sharpe ratio on an artificial asset generated with a set of betas listed in Table 2 of the separate appendix, but with intercept $\beta_{0}^{j}$ chosen so that the Euler equation is satisfied for this asset in the model. The parametrization is the benchmark one. The first block corresponds to the betas obtained using the mortgage-based measure; the second block uses the residential wealth-based measure. Panel 3 reports the results of the duration-based asset pricing exercise of section 5.2 . It reports equity premia (second row), their volatilities (third row), and Sharpe ratios (fourth row) for 10 portfolios of different duration (first row). The leverage parameter $\kappa$ is 2 .

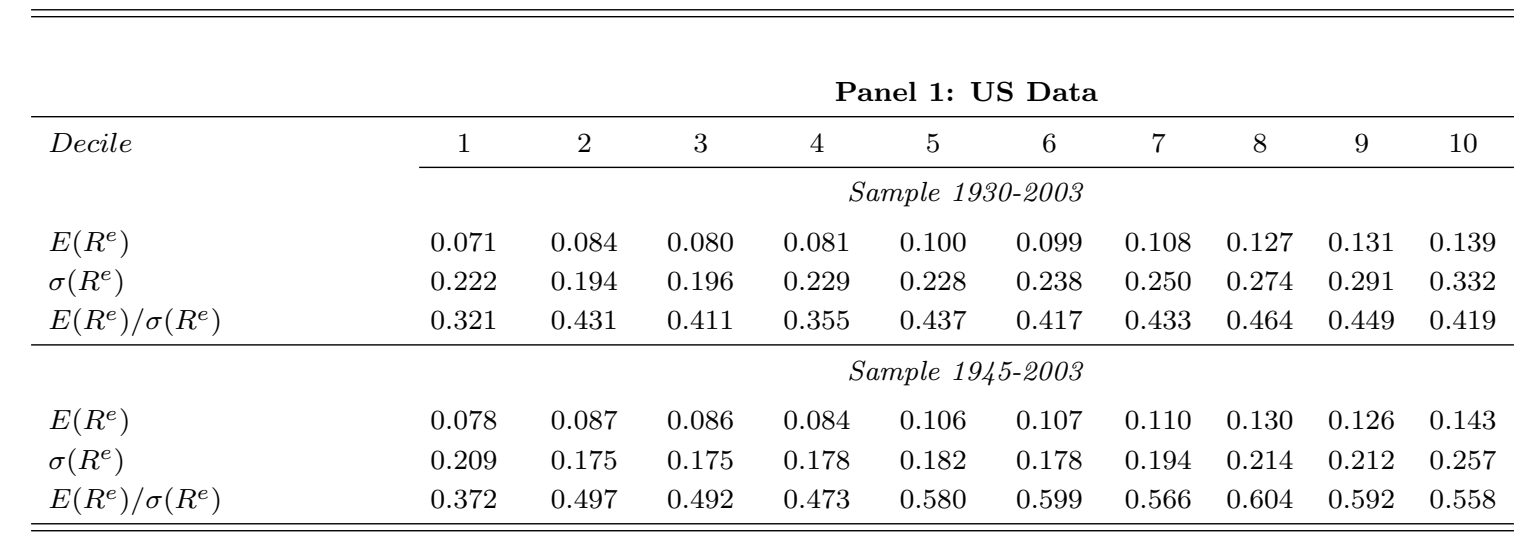

Panel 2: Model with Empirical Betas

\begin{tabular}{lcccccccccccc}
\hline Decile & 1 & 2 & 3 & 4 & 5 & 6 & 7 & 8 & 9 & 10 \\
\cline { 2 - 10 } & & \multicolumn{7}{c}{ Mortgage-Based Collateral Measure } \\
$E\left(R^{e}\right)$ & -0.002 & 0.007 & 0.018 & 0.018 & 0.021 & 0.034 & 0.060 & 0.042 & 0.052 & 0.066 \\
$\sigma\left(R^{e}\right)$ & 0.104 & 0.065 & 0.081 & 0.093 & 0.107 & 0.110 & 0.145 & 0.130 & 0.123 & 0.153 \\
$E\left(R^{e}\right) / \sigma\left(R^{e}\right)$ & -0.020 & 0.115 & 0.226 & 0.190 & 0.200 & 0.309 & 0.418 & 0.322 & 0.422 & 0.433 \\
\hline & & & Residential Wealth-Based Collateral Measure & \\
$E\left(R^{e}\right)$ & 0.001 & 0.015 & 0.022 & 0.029 & 0.028 & 0.051 & 0.080 & 0.055 & 0.072 & 0.085 \\
$\sigma\left(R^{e}\right)$ & 0.116 & 0.062 & 0.076 & 0.088 & 0.106 & 0.131 & 0.178 & 0.149 & 0.159 & 0.191 \\
$E\left(R^{e}\right) / \sigma\left(R^{e}\right)$ & 0.011 & 0.241 & 0.286 & 0.323 & 0.266 & 0.387 & 0.453 & 0.370 & 0.451 & 0.448 \\
\hline \hline
\end{tabular}

Panel 3: Model with Duration-Based Pricing

\begin{tabular}{lcccccccccc}
\hline Duration & 43.387 & 42.529 & 39.476 & 32.166 & 20.274 & 13.145 & 8.870 & 4.759 & 3.040 & 2.328 \\
\cline { 2 - 9 }$E\left[R^{e}\right]$ & 0.025 & 0.027 & 0.034 & 0.049 & 0.068 & 0.075 & 0.077 & 0.073 & 0.067 & 0.061 \\
$\sigma\left[R^{e}\right]$ & 0.191 & 0.193 & 0.196 & 0.202 & 0.202 & 0.198 & 0.192 & 0.175 & 0.157 & 0.142 \\
$E\left[R^{e}\right] / \sigma\left[R^{e}\right]$ & 0.130 & 0.138 & 0.171 & 0.242 & 0.336 & 0.381 & 0.402 & 0.416 & 0.424 & 0.431 \\
& & & & & & & & & & \\
\hline \hline
\end{tabular}




\section{A Technical Appendix}

This section contains the proofs of the propositions in the main text. For more details on the model (definition of the cumulative multipliers, derivation and optimality of the risk sharing rule and the optimality of the law of motion for the cumulative multipliers), we refer the reader to section 2 of the separate appendix to this paper, available on our web sites.

Proof of Proposition 1 Following the definition of Alvarez and Jermann (2005), the pricing kernel $M$ has no permanent component if

$$
\lim _{k \rightarrow \infty} \frac{E_{t+1} M_{t+k}}{E_{t} M_{t+k}}=1 .
$$

We focus on a slightly different condition:

$$
\lim _{k \rightarrow \infty} \frac{E_{t+1} M_{t+k} c_{t+k}}{E_{t} M_{t+k} c_{t+k}}=1
$$

Let the one period holding return on a period-k consumption strip be given by:

$$
R_{t+1, k}^{c}=\frac{M_{t}}{M_{t+1}} \frac{E_{t+1} M_{t+k} c_{t+k}}{E_{t} M_{t+k} c_{t+k}}
$$

then we know, from the derivation above, that

$$
\lim _{k \rightarrow \infty} R_{t+1, k}^{c}=\frac{M_{t}}{M_{t+1}} .
$$

Furthermore, for any return $E_{t}\left[\frac{M_{t+1}}{M_{t}} R_{t+1}\right]=1$, we know that $E_{t}\left[\log \left(\frac{M_{t+1}}{M_{t}} R_{t+1}\right)\right] \leq \log E_{t}\left[\frac{M_{t+1}}{M_{t}} R_{t+1}\right]=$ 0 by Jensen's inequality. This implies that $E_{t} \log \left(\frac{M_{t}}{M_{t+1}}\right) \geq E_{t} \log \left(R_{t+1}\right)$ or

$$
E_{t} \log \lim _{k \rightarrow \infty} R_{t+1, k}^{c}=\log \frac{M_{t}}{M_{t+1}} \geq E_{t} \log \left(R_{t+1}\right) \text { for any asset return } R_{t+1}
$$

This implies that the expected log excess return exceeds that any other asset:

$$
E_{t} \log \lim _{k \rightarrow \infty} \frac{R_{t+1, k}^{c}}{R_{t+1,1}} \geq E_{t} \log \frac{\left(R_{t+1}\right)}{R_{t+1,1}}
$$

Let $f(k)=C e^{a k}$ with $a>0$ for growth stocks. In the absence of a permanent component in the pricing kernel:

$$
\lim _{a \rightarrow \infty} 1+\widetilde{\nu}_{0}=\lim _{k \rightarrow \infty} R_{t+1, k}^{c} \geq 1+\nu_{0} \text { for any other sequence of weights }\left\{\omega_{k}\right\}
$$

This implies that the highest equity premium is the one on the farthest out consumption strip. In the absence of a permanent component in the pricing kernel, there is a growth premium. 
Derivation of Value Premium The multiplicative risk premium on an (un-levered) consumption strip is derived as follows:

$$
\begin{aligned}
1+\nu_{0}=1+E_{0}\left[R_{0,1}^{e}\left[\left\{c_{k}\right\}\right]\right] & =E_{0} M_{1} E_{0}\left(\frac{\sum_{k=1}^{\infty} E_{1} M_{k} c_{k}}{\sum_{k=1}^{\infty} E_{0} M_{k} c_{k}}\right)=\sum_{k=1}^{\infty} \frac{E_{0} M_{k} c_{k}}{\sum_{k=1}^{\infty} E_{0} M_{k} c_{k}} \frac{\frac{E_{1} M_{k} c_{k}}{E_{0} M_{k} c_{k}}}{\frac{1}{E_{0} M_{1}}} \\
& =\sum_{k=1}^{\infty} \omega_{k} \frac{E_{0} R_{0,1}\left[c_{k}\right]}{R_{0,1}[1]}=\sum_{k=1}^{\infty} \omega_{k} E_{0} R_{0,1}^{e}\left[c_{k}\right]
\end{aligned}
$$

with weights

$$
\omega_{k}=\frac{E_{0} M_{k} c_{k}}{\sum_{k=1}^{\infty} E_{0} M_{k} c_{k}}
$$

Condition 1 Section F.1 in the separate appendix explains the equivalence between the static and sequential budget constraints and solvency constraints. This equivalence holds only if interest rates are high enough (see Alvarez and Jermann (2000)). We impose the following condition. Let $\eta_{\max }$ denote the highest possible labor endowment realization in each future, aggregate node $z^{t}$.

Condition 1. Interest rates are said to be high enough if

$$
\Pi_{z_{0}, y_{0}}\left[\left\{\eta_{\max }\right\}\right]<\infty
$$

This is the equivalent of the condition in Alvarez and Jermann (2000) that interest rates be high enough, translated to an economy with a continuum of consumers. In an economy with a finite number of agents, it is sufficient to require the time zero value of a claim to the aggregate endowment to be finite, but here it is not sufficient for the value of a claim to the average endowment to be finite.

Proof of Proposition 2 Denote the price of a claim under perfect risk-sharing by $\Pi^{*}[\{\cdot\}]$. Perfect risk sharing can be sustained if and only if

$$
\Pi_{z}^{*}\left[\left\{c^{a}\left(1+\frac{1}{r}\right)\right\}\right] \geq \Pi_{z, y}^{*}[\{\eta(y, z)\}]
$$

for all $(y, z, r)$ with nonzero measure; $\Phi$ is the joint measure defined on $\mathcal{P}(Y) \times \mathcal{P}(Z) \times \mathcal{B}(R)$. If this condition is satisfied, each household can get a constant and equal share of the aggregate non-durable and housing endowment at all future nodes. That immediately implies that perfect risk-sharing is feasible. If there is a value $r_{\max }$ such that any $r^{\prime}>r_{\max }$ is measure zero, then perfect risk sharing can be sustained if

$$
\Pi_{z}^{*}\left[\left\{c^{a}(z)\left(1+r_{\max }^{-1}\right)\right\}\right] \geq \Pi_{z, y}^{*}[\{\eta(y, z)\}] \text { for all }(y, z) \in Y \times Z
$$

This condition is sufficient, but not necessary. 
Proof of Proposition 3 Assume utility is separable. Let $C\left(\ell, y_{t}, z^{t}\right)$ denote the cost of claim to consumption in state $\left(y_{t}, z^{t}\right)$ for a household who enters the period with weight $\xi$. The cutoff rule $\underline{\xi}\left(y_{t}, z^{t}\right)$ is determined such that the solvency constrain binds exactly: $\Pi_{y, z^{t}}[\{\eta\}]=C\left(\underline{\xi}, y_{t}, z^{t}\right)$, where $C\left(\xi, y_{t}, z^{t}\right)$ is defined recursively as:

$C\left(\xi, y_{t}, z^{t}\right)=\frac{\xi\left(y_{t}, z^{t}\right)}{\xi_{t}^{a}\left(z^{t}\right)}\left(1+\frac{1}{r_{t}}\right)+\delta \sum_{z_{t+1}} \pi\left(z_{t+1} \mid z_{t}\right) \sum_{y^{\prime}} \frac{\pi\left(y_{t+1}, z_{t+1} \mid y_{t}, z_{t}\right)}{\pi\left(z_{t+1} \mid z_{t}\right)} m_{t+1}\left(z^{t+1}\right) C\left(\xi^{\prime}, y_{t+1}, z^{t+1}\right)$,

and $\xi^{\prime}$ is determined by the cutoff rule (10). Note that the stochastic discount factor $m_{t+1}\left(z^{t+1}\right)$ does not depend on $r_{t}\left(z^{t}\right)$ because we assumed that utility is separable. This also implies that the cost of a claim to labor income $\Pi_{y, z^{t}}[\{\eta\}]$ does not depend on $r$.

We prove the result for a finite horizon version of this economy. We first assume some arbitrary state prices $\left\{p_{t}\left(s^{t} \mid s_{0}\right)\right\}$ for both of these economies. $\left\{m_{t}\left(z^{t}\right)\right\}$ denotes the SDF process implied by these state prices. Finally, we use $T^{i}$ to denote the operator that maps the aggregate weight functions $\left\{\xi_{t}^{a}\left(z^{t}\right)\right\}$ we start with into a new aggregate function $\left\{\xi_{t}^{\prime, a}\left(z^{t}\right)\right\}$.

In the last period $T$, the cutoff rule is determined such that:

$$
\begin{array}{r}
\eta\left(y_{T-1}, z^{T-1}\right)=\frac{\xi\left(y_{T-1}, z^{T-1}\right)}{\xi_{T}^{a}\left(z^{T-1}\right)}\left(1+\frac{1}{r_{T-1}\left(z^{T-1}\right)}\right)+\delta \sum_{z_{t+1}} \pi\left(z_{T} \mid z_{T-1}\right) \\
\sum_{y^{\prime}} \frac{\pi\left(y_{T}, z_{T} \mid y_{T-1}, z_{T-1}\right)}{\pi\left(z_{T} \mid z_{T-1}\right)} m_{T}\left(z^{T} \mid z_{T-1}\right)\left(\frac{\xi^{\prime / \gamma}}{\xi_{T}^{a}\left(z^{T}\right)}\left(1+\frac{1}{r_{T}\left(z^{T}\right)}\right)-\eta\left(y_{T}, z^{T}\right)\right.
\end{array}
$$

where $\frac{\xi^{\prime 1 / \gamma}}{\xi_{T}^{a}\left(z^{T}\right)}\left(1+\frac{1}{r_{T}}\right) \geq \eta\left(y_{T}, z^{T}\right)$. Given $r_{T}^{1}<r_{T}^{2}$ and $r_{T-1}^{1}\left(z^{T-1}\right)<r_{T-1}^{2}\left(z^{T-1}\right)$, this implies that $\ell^{1, c}\left(y_{T-1}, z^{T-1}\right)<\ell^{2, c}\left(y_{T-1}, z^{T-1}\right)$ for all $\left(y_{T-1}, z^{T-1}\right)$. By backward induction we get that, for a given sequence of $\left\{\xi_{t}^{a}\left(z^{t}\right)\right\}, \ell^{1, c}\left(y_{t}, z^{t}\right)<\ell^{2, c}\left(y_{t}, z^{t}\right)$ for all nodes $\left(y_{t}, z^{t}\right)$ in the finite horizon economy. This in turn implies that $T^{1}\left(\left\{\xi_{t}^{a}\left(z^{t}\right)\right\}\right) \leq T^{2}\left(\left\{\xi_{t}^{a}\left(z^{t}\right)\right\}\right)$ for all $z^{t}$, with strict inequality if at least one of the constraints binds. This follows directly from the definition of

$$
\begin{aligned}
\xi_{t}^{a}\left(z^{t}\right)= & \sum_{y^{t}} \int \xi_{t}\left(\ell, y^{t}, z^{t}\right) \frac{\pi\left(z^{t}, y^{t} \mid z_{0}, y_{0}\right)}{\pi\left(z^{t} \mid z_{0}\right)} d \Phi_{0} \\
= & \sum_{y^{t}} \int_{\underline{\xi}\left(y_{t}, z^{t}\right)} \xi_{t-1}\left(\ell, y^{t}, z^{t}\right) \frac{\pi\left(z^{t}, y^{t} \mid z_{0}, y_{0}\right)}{\pi\left(z^{t} \mid z_{0}\right)} d \Phi_{0} \\
& +\sum_{y^{t}} \int^{\underline{\xi}\left(y_{t}, z^{t}\right)} \underline{\xi}\left(y_{t}, z^{t}\right) \frac{\pi\left(z^{t}, y^{t} \mid z_{0}, y_{0}\right)}{\pi\left(z^{t} \mid z_{0}\right)} d \Phi_{0}
\end{aligned}
$$

$\xi_{t}^{a}\left(z^{t}\right)$ is non-decreasing in $\xi\left(y_{t}, z^{t}\right)$. The proof extends to the infinite horizon economy if the transition matrix has no absorbing states. The reason is that $\lim _{T \rightarrow \infty} E_{t}\left[\beta^{T-t} m_{T}\left(z^{T} \mid z_{t}\right) \pi_{z^{T}, y_{T}}\right]$ does not depend on the current state $\left(y_{t}, z_{t}\right)$. Now, this also implies a new state price function, for 
each $s^{t}$ :

$$
p_{t}^{\prime}\left(s^{t} \mid s_{0}\right)=p_{t}^{a}\left(s^{t} \mid s_{0}\right){\frac{\xi_{t}^{a}\left(z^{t}\right)^{\gamma}}{\xi_{0}^{a}\left(z^{0}\right)}}^{\gamma}
$$

where $p_{t}^{a}\left(s^{t} \mid s_{0}\right)$ is the representative agent state price. So if we start with the equilibrium state prices for the second economy $\left\{p_{t}^{2}\left(s^{t} \mid s_{0}\right)\right\}$, the implied aggregate weights for the first economy will be smaller:

$$
T^{1}\left(\left\{\xi_{t}^{2, a}\left(z^{t}\right)^{\star}\right\}\right)<\left\{\xi_{t}^{2, a}\left(z^{t}\right)^{\star}\right\}=T^{2}\left(\left\{\xi_{t}^{2, a}\left(z^{t}\right)^{\star}\right\}\right),
$$

where the last equality follows because we started with the equilibrium prices for the second economy, and similarly,

$$
T^{1}\left(\left\{\xi_{t}^{1, a}\left(z^{t}\right)^{\star}\right\}\right)=\left\{\xi_{t}^{1, a}\left(z^{t}\right)^{\star}\right\}<T^{2}\left(\left\{\xi_{t}^{1, a}\left(z^{t}\right)^{\star}\right\}\right),
$$

if we start with the equilibrium prices in the first economy. Now, it can be shown that $T^{i}\left(\left\{\xi_{t}^{\prime}\left(z^{t}\right)\right\}\right) \leq$ $T^{i}\left(\left\{\xi_{t}\left(z^{t}\right)\right\}\right)$ if $\left\{\xi_{t}^{\prime}\left(z^{t}\right)\right\}>\left\{\xi_{t}\left(z^{t}\right)\right\}$ (Lustig (2003). Finally, using the previous results:

$$
T^{1}\left(\left\{\xi_{t}^{2, a}\left(z^{t}\right)^{\star}\right\}\right)<\left\{\xi_{t}^{2, a}\left(z^{t}\right)^{\star}\right\} \text { and } T^{1}\left(\left\{\xi_{t}^{1, a}\left(z^{t}\right)^{\star}\right\}\right)=\left\{\xi_{t}^{1, a}\left(z^{t}\right)^{\star}\right\}
$$

we obtain that $\left\{\xi_{t}^{1, a}\left(z^{t}\right)^{\star}\right\}<\left\{\xi_{t}^{2, a}\left(z^{t}\right)^{\star}\right\}$.

Proof of Corollary 1 Follows from the definition of the cutoff level in the previous proof. For a given sequence of $\left\{\xi_{t}^{a}\left(z^{t}\right)\right\}$, it is obvious that $\ell^{1, c}\left(y_{t}, z^{t}\right)<\ell^{2, c}\left(y_{t}, z^{t}\right)$ for all nodes $\left(y_{t}, z^{t}\right)$. This in turn implies that $\left\{\xi_{t}^{a, 1}\left(z^{t}\right)\right\} \leq\left\{\xi_{t}^{a, 2}\left(z^{t}\right)\right\}$. This follows directly from the definition of the aggregate weight shock (14). As a result, $\xi_{t}^{a}\left(z^{t}\right)$ is non-decreasing in $\underline{\xi}\left(y_{t}, z^{t}\right)$. This implies the state prices at time 0 for consumption to be delivered in $s^{t}$ are higher, and this is true for all nodes $s^{t}$.

Interest rates between time zero and time $\mathrm{t}$ are given by $R_{0, t}^{f}=E_{0}\left[M_{0, t}\right]^{-1}$, where the pricing kernel between time 0 and time $\mathrm{t}$ is $M_{0, t}=m_{0} \cdot m_{1} \cdots m_{t}$. A lower aggregate weight shock $\frac{\xi_{t}^{a}}{\xi_{0}^{a}}$ at time $t$ in all nodes $s^{t}$ implies a lower pricing kernel on average and higher interest rates on average.

\section{B Asset Value Approach to Calibrating Housing Col- lateral Ratio}

In the main text we used factor payments on collateralizable and non collateralizable wealth to calibrate the housing collateral ratio. Those data were taken from Table 1.12. National Income by Type of Income (NIPA), except for the net interest series which comes from Table 1.13 (net interest paid by domestic corporations, line 8). Here we describe a second approach, based on measuring collateral wealth directly. More precisely, we compare the ratio of collateral wealth to total income in the model and in the data.

We start by measuring the collateral wealth-to-income ratio in the data. Housing collateral wealth is measured as the market value of outstanding mortgages. The residential mortgage series 
is from the Flow of Funds Tables and is available for the post-war period. Over that period, the average ratio of residential mortgages to labor income plus rental income is 0.55 . Financial wealth is measured as the market value of non-farm non-financial corporations in the US This series is constructed based on Flow of Funds data; Lustig and Van Nieuwerburgh (2005c) provides the details. Our broad measure of total collateral wealth to total income is constructed as the ratio of residential mortgages plus financial wealth to labor income plus interest income plus dividend income plus proprietor's income. That ratio is 1.55 in post-war data.

We compare these numbers to the housing collateral wealth-to-income ratio in the model. More precisely, we fix an average housing collateral ratio $m y$, simulate the model for a long period, and compute the housing wealth to total income ratio. When $m y=0.05$, the collateral wealth to income ratio is 0.90 , in between the narrow and the broad empirical measure.

What is the effect of a higher housing collateral ratio in the model? When my is higher than 0.05, the collateral wealth-to-income ratio is actually lower than 0.90 . To understand this, consider the Gordon growth formula:

$$
\frac{\text { collateral wealth }}{\text { total income }}=\frac{\frac{\text { collateral income }}{\text { total income }}}{R-g}
$$

where $R$ is the expected rate of return on total wealth and $g$ is the growth rate of total income. The numerator is effectively the housing collateral ratio, for example 0.075. In the denominator, the aggregate endowment growth rate $g$ is the same across calibrations. Not so for the discount rate $R$. This discount rate is the sum of the risk premium on a claim to aggregate consumption (the equity premium) and the risk-free rate. In an economy with more collateral, the equity premium goes down, but the interest rate goes up. This interest rate effect dominates the risk premium effect, so that the denominator is increasing in $m y$. It does not help to increase $m y$ to generate a large collateral wealth to total income ratio. We find a higher wealth to income ratio of 0.96 for $m y=0.035$ than the 0.90 for $m y=0.05$ and the 0.84 for $m y=0.075$.

The main point is that, with a five percent collateral ratio, our benchmark model allows for a lot of collateral: $90 \%$ of the value of national income on average.

\section{Computing Stationary Equilibria}

In this appendix we show how to compute stationary equilibria. As we noted in section 5 , the aggregate weight shock depends on the entire history of aggregate shocks $z^{\infty}$. To avoid the curse of dimensionality, we follow Lustig (2003) and truncate aggregate histories. Households only keep track of the last $k$ lags of the aggregate state, $z_{t}^{k}=\left(z_{t}, z_{t-1}, \cdots, z_{t-k}\right)$, and the current expenditure ratio $r_{t}\left(z^{t}\right)$. The current expenditure ratio $r_{t}$ contains additional information not present in the truncated history $z_{t}^{k}$, namely $r_{t-k}$. For a household starting the period with weight $\xi \in \Xi$, the policy function $l\left(y^{\prime}, z^{\prime} ; \xi, r, z^{k}\right): \Xi \times \mathcal{R} \times Z^{k} \rightarrow \mathbb{R}$ produces the new individual weight in state $\left(y^{\prime}, z^{\prime}\right)$. There is one policy function $l(\cdot)$ for each pair $\left(y^{\prime}, z^{\prime}\right) \in Y \times Z$. The policy function 
$g^{*}\left(z^{\prime} ; r, z^{k}\right): \mathcal{R} \times Z^{k} \rightarrow \mathbb{R}$ forecasts the aggregate weight shock when moving to state $z^{\prime}$ after history $\left(z^{k}, r\right)$.

Competitive Equilibrium. A stationary stochastic equilibrium is a time invariant distribution $\Phi_{\left(r, z^{k}\right)}^{*}(\xi, y)$ over individual weights, individual endowments, current expenditure ratio, and truncated aggregate histories, and updating rules $l(\cdot)$ and $g^{*}(\cdot)$. For each $\left(z^{k \prime}, z^{k}\right)$ with $z^{k \prime}=\left(z^{\prime}, z^{k}\right)$, the distribution satisfies:

$$
\Phi_{\left(r, z^{k \prime}\right)}^{*}=\sum_{z^{k}} \pi\left(z^{k \prime} \mid z^{k}\right) \int Q\left(\xi, y, r, z^{k}\right) \Phi_{\left(r, z^{k}\right)}^{*}(d \xi \times d y)
$$

where $Q\left(\xi, y, r, z^{k}\right)$ is the transition function induced by the policy functions. The forecast of the aggregate weight shock is given by:

$$
g^{*}\left(z^{\prime} ; r, z^{k}\right)=\sum_{y^{\prime} \in Y} \int l\left(y^{\prime}, z^{\prime} ; \xi, r, z^{k}\right)^{\frac{1}{\gamma}} \Phi_{r, z^{k}}^{*}(d \xi \times d y) \frac{\pi\left(y^{\prime}, z^{\prime} \mid y, z\right)}{\pi\left(z^{\prime} \mid z\right)}, \forall z^{\prime} \in Z .
$$

Intertemporal prices are pinned down by the stochastic discount factor in equation (12), using the forecasted shock $g^{*}(\cdot)$ as an approximation to the actual $g(\cdot)$. For any given realization $\{z\}$, the actual aggregate weight shock $g(\cdot)$ differs from the forecast $g^{*}(\cdot)$ because the distribution over individual weights and endowments $\Phi^{*}(\cdot)$ differs from the actual distribution $\Phi(\cdot)$, which depends on $z^{\infty}$. The definition of a stationary equilibrium implies that, on average, across aggregate histories, $\Phi^{*}(\cdot)=\Phi(\cdot)$ and markets clear: The difference between actual consumption and consumption based on a truncated history is zero on average, but not state-by-state. In each state $z^{\prime}$, the approximation error equals the percentage difference between the actual aggregate weight shock and aggregate weight shock based on a truncated history:

$$
c^{a}\left(z^{\prime} ; r, z^{k}\right)-c^{a}\left(z^{\prime} ; z^{\infty}\right)=\frac{g^{*}\left(z^{\prime} ; r, z^{k}\right)-g\left(z^{\prime} ; r, z^{\infty}\right)}{g^{*}\left(z^{\prime} ; r, z^{k}\right)}
$$

This is the difference between consumption and the endowment. As the truncation parameter $k$ increases, the approximation error decreases because market clearing holds on average in long histories. We use $k=5$ lags in all our computations. The percentage allocation errors in (15) provide a clear measure of the closeness to the actual equilibrium. For our benchmark calibration, the average error in a simulation of 10,000 periods is only 0.0011 with standard deviation .0035 . The largest error in absolute value is 0.0282 .

We compute the approximating equilibrium as follows. The aggregate weight shock process is initialized at the full insurance value $\left(g^{*}=1\right)$ and the corresponding stochastic discount factor is computed. The cutoff rule for the individual weight shocks ensure that the solvency constraints hold with equality. Then we generate a panel of data by simulating the model: $\left\{z_{t}\right\}_{t=1}^{T}$ for $T=$ 10,000 and $\left\{y_{t}\right\}_{t=1}^{T}$ for a cross-section of 5,000 households. For each truncated history, we store $\left\{\frac{l\left(y^{\prime}, z^{\prime} ; \xi, r, z^{k}\right)^{\frac{1}{\gamma}}}{g^{*}\left(z^{\prime} ; r, z^{k}\right)}\right\}$ as the household's identifying label $\xi$ (the re-scaling keeps the state variables 
stationary), and compute the sample mean of the aggregate weight shock $\left\{g_{t}^{*}\left(z^{\prime}, r, z^{k}\right)\right\}_{t=1}^{T}$ and the resulting stochastic discount factor $\left\{m_{t}^{*}\left(z^{\prime}, r, z^{k}\right)\right\}_{t=1}^{T}$. A new cut-off rule is computed with these new forecasts. These two steps are iterated on until convergence.

\section{Unconditional Asset Pricing Moments}

The model succeeds in matching most unconditional asset pricing moments, when we set $\gamma$ equal to eight, except for the volatility of the risk-free rate.

Risk Premium Table 7 compares the unconditional first and second moments of asset returns in US data (panel 1), in the collateral model (panels 2 and 4), and in the representative agent model (panel 3). The benchmark calibration in panel 2 generates a $8.6 \%$ risk premium on an un-levered equity claim, with a volatility of $21.7 \%$. These numbers line up with the $7.9 \%$ excess return in the data and its $20.7 \%$ volatility. The Sharpe ratio is 0.397 , close to the 0.384 Sharpe ratio observed in 1927-2004. Because consumption growth is less volatile in the data than dividend growth, we also compute a levered claim to aggregate consumption in the model $(\kappa=3)$. The model with lower risk aversion $(\gamma=5)$ now also generates a sizeable and volatile (levered) risk premium: $3.9 \%$ expected excess return with $16.7 \%$ standard deviation. We contrast this with a representative agent economy. The equity premium on an un-levered (levered) consumption claim is less than one-third (one-half) as big as in the collateral model, even though preferences are non-separable between non-housing and housing consumption. Finally, doubling the collateral ratio to $10 \%$ brings this economy closer to the representative agent economy because the solvency constraints are looser. The expected excess return on a levered consumption claim is still high (5.7\%) and volatile (21\%) for $(\gamma=8, \varepsilon=.05)$.

[Table 7 about here.]

Risk-free Rate The model with $\gamma=8(\gamma=5)$ generates an average risk free rate of $2.6 \%$ (7.7\%), close to the $1.9 \%$ in the 1871-1979 data. The risk of binding collateral constraints increases the expected SDF more when risk aversion $\gamma$ is high, and pushes down the risk-free rate. There are two reasons for this fall in the risk-free rate: Households cannot borrow as much, and they accumulate more precautionary savings. When households are more risk averse, the precautionary motive is stronger. They bid up the price of risk-free assets which provide insurance against the risk of binding constraints. In contrast, the risk-free rate increases with $\gamma$ in the representative agent economy (panel 3). A more risk-averse representative agent is less willing to substitute intertemporally and wants to borrow more against growing labor income; this drives up the risk-free rate. The level of the risk-free rate is much too high: $15.8 \%$ in the benchmark calibration.

The biggest shortcoming of the collateral model is the high unconditional volatility of the riskfree rate. It is $7 \%$ in the economy with $\gamma=5,15.6 \%$ in the economy with $\gamma=8$, but only $4.2 \%$ in the 1927-2002 data and 5.2\% in the 1871-1979 data. When the average collateral ratio is 10\% instead, 
the risk-free rate is higher but less volatile (panel 4). Two forces drive this volatility: variation in the expected fraction of households facing binding constraints due to shocks to the wealth distribution (at higher frequencies), and shocks to the risk-sharing technology due to changes in value of housing collateral (at lower frequencies). Both modulate the demand for insurance. As we argued in section 3 , the model does generate a large decline in the risk-free rate volatility between the 1930s and the 1990s, consistent with the data.

Sensitivity: Recursive Utility One way to mitigate the risk-free rate volatility is to use recursive preferences to de-couple risk aversion from the willingness to substitute consumption over time. Raising the intertemporal elasticity of substitution of 0.2 (with $\gamma=8$ ) reduces the volatility of the risk-free rate from $15.6 \%$ to $6.9 \%$ (panel 5 ). The equity premium is still $4.9 \%$ with a volatility of $19.5 \%$.The separate appendix reports more detailed results.

Sensitivity: Composition Effect A higher intratemporal elasticity of substitution $(\varepsilon)$ increases the equity premium and the Sharpe ratio and lowers the risk-free rate (panel 6). This effect also shows up in the representative agent economy; Piazzesi et al. (2004) refer to it as a negative composition effect. Assets that pay off in low non-housing expenditure share growth states are risky as such states occur in recessions (see equation 16). An increase in $\varepsilon$ from .05 to .75 increases the equity premium by $4 \%$ and decreases the risk-free rate by $4 \%$ in both our model and the representative agent economy. Detailed results for the representative agent economy are available upon request. However, these empirically plausible return moments come at the expense of an implausibly high rental price growth volatility. For $\varepsilon=.75$, the rental price growth volatility $\sigma(\Delta \log \rho)$ is $19 \%$ per annum (see equation 7 ), whereas observed rental price growth volatility is below $5 \%$.Driving $\varepsilon$ even closer to 1 leads to exponentially increasing rental price growth volatility. For $\varepsilon>1$ the representative agent model generates a negative equity premium. We choose $\varepsilon=.05$ for our benchmark calibration because the rental price growth volatility then matches the data. A higher $\varepsilon$ also increases risk-free rate volatility.

\section{Sensitivity: Risk Aversion, Expenditure Share, and Income Heteroscedasticity} Varying the coefficient of relative risk aversion $\gamma$ from 2 to 10 (panel 7) increases the equity premium on a levered (non-levered) consumption claim from $0.8 \%$ to $15.7 \%$ (.3\% to 13.3\%). The Sharpe ratio increases from .07 to 0.55 . The risk-free rate falls from $8.6 \%$ to $-2.1 \%$. When the expenditure share does not depend on consumption growth $\left(b_{r}=0\right.$ in equation 16$)$, the housing collateral ratio becomes less volatile. The equity risk premium is now $6.9 \%$ with volatility $23.7 \%$. The risk-free rate is $1.8 \%$, and its volatility is $3 \%$ lower than in the benchmark model (panel 8 ). Finally, we shut down the Mankiw (1986) mechanism by having income shocks with the same dispersion in booms as in recessions (panel 9). The housing collateral mechanism alone generates a sizeable 5.7\% equity premium. The risk-free rate is $5 \%$ higher, but $5 \%$ less volatile. We argued earlier that it is important to have both the collateral effect and the counter-cyclical income dispersion at work to generate a value premium. 